\title{
Fluoromethoxymethylation of Nitrogen Heterocyclic Compounds with Fluoromethyl Iodide
}

\author{
Rongkang Wang, Tianqi Ding, Lvqi Jiang*, Wujuan He, Wenbin Yi*
}

Table of Contents

1. Mechanistic Studies.................................................. 2

2. NMR Spectra...................................................... 4

3. X-Ray Crystallographic Data of 3q..................................S46 


\section{Mechanistic Studies}

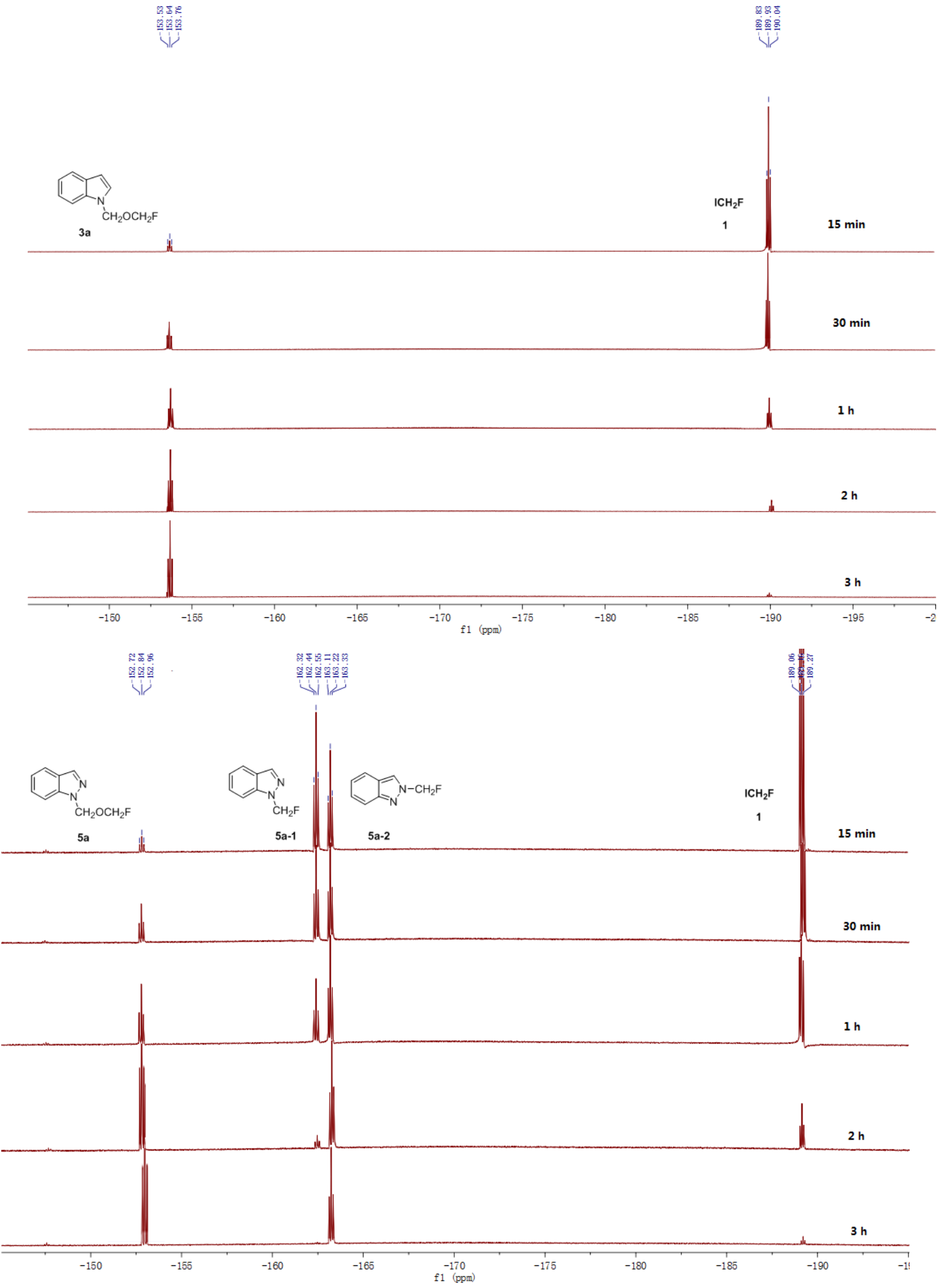




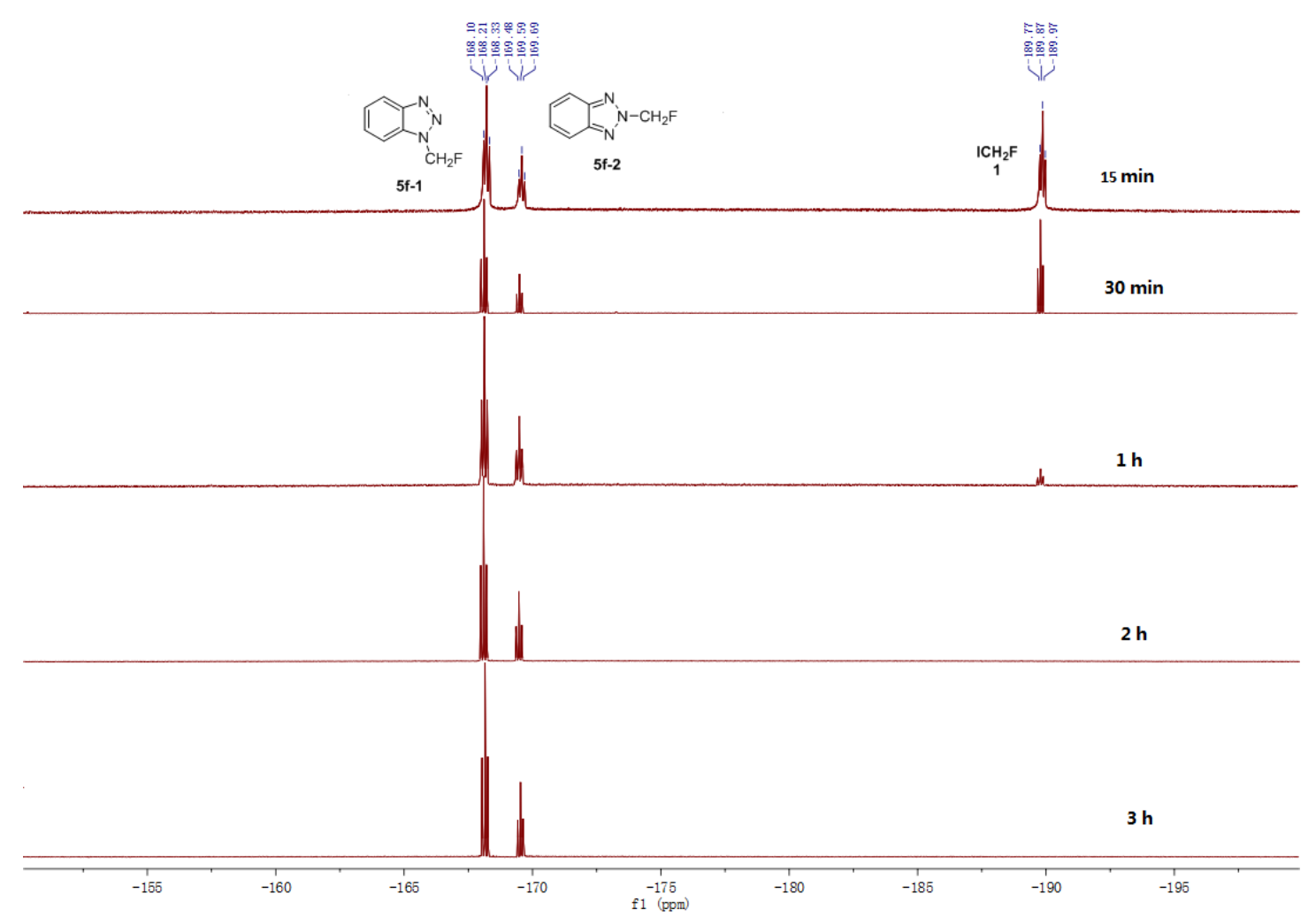

Figure S1. Progress of the reaction of $\mathbf{2 a}, \mathbf{4 a}$ and $\mathbf{4 f}$, for up to $3 \mathrm{~h}$, by ${ }^{19} \mathrm{~F}$ NMR spectroscopy.

To understand the mechanism of this fluoromethoxymethyl reaction, we decided to trace the reactions by ${ }^{19} \mathrm{~F}$ NMR in three cases $(\mathbf{2 a}, \mathbf{4 a}$ and $\mathbf{4 f})$. The results were displayed in Figure S1. During the 3 hours reaction process of reaction with $\mathbf{2 a}$, only two singals including those for the reagent $\mathbf{1}(\delta-189.9 \mathrm{ppm})$ and product $\mathbf{3 a}(\delta-153.6$ ppm) were observed. The amount of $\mathrm{ICH}_{2} \mathrm{~F}$ decreased and the desired product 3a increased during the reaction process. For $1 H$-indazole $4 \mathbf{a}$, the signals were very different. In spite of reagent $\mathbf{1}$ and product 5a, two new singals were obtained: $\delta$ -162.5 ppm (5a-1) and $\delta-163.2$ ppm (5a-2), which were two $\mathrm{CH}_{2} \mathrm{~F}$-substituted products ${ }^{1}$. It was obvious that 5a-1 decreased accompanied by the increase of product 5a, while another signal of $\delta-163.2 \mathrm{ppm}$ (5a-2) was observed with no significant change. This indicated that only one $\mathrm{CH}_{2} \mathrm{~F}$-substituted intermediate (5a-1) could convert to the final product $\mathbf{5 a} .^{2}$ For the case of $1 H$-benzotriazole $\mathbf{4 f}$, it was similar that two $\mathrm{CH}_{2} \mathrm{~F}$-substituted products $\mathbf{5 f - 1}(\delta-168.2 \mathrm{ppm})$ and $\mathbf{5 f - 2}(\delta-169.6 \mathrm{ppm})$ were observed, but neither could transfer to the $\mathrm{CH}_{2} \mathrm{OCH}_{2} \mathrm{~F}$ product.

\section{References:}

1. Zhang, W.; Zhu, L.; Hu, J. Electrophilic monofluoromethylation of O-, S-, and N-nucleophiles with chlorofluoromethane. Tetrahedron. 2007, 63, 10569-10575.

2. The structure of $\mathrm{CH}_{2} \mathrm{~F}$-substituted intermediates $\mathbf{5 a - 1}$ and $\mathbf{5 a - 2}$ were confirmed by comparing ${ }^{13} \mathrm{C}$ NMR spectra with the similar $\mathrm{CH}_{3}$-substituted compounds: a) Cheung, M.; Boloor, A.; Stafford, J. A. Efficient and Regioselective Synthesis of 2-Alkyl-2H-indazoles. J. Org. Chem. 2003, 68, 4093-4095; b) Liu, H.-J.; Hung, S.-F.; Chen, C.-L.; Lin, M.-H. A method for the regioselective synthesis of 1-alkyl-1H-indazoles. Tetrahedron. 2013, 69, 3907-3912. 


\section{NMR Spectra}

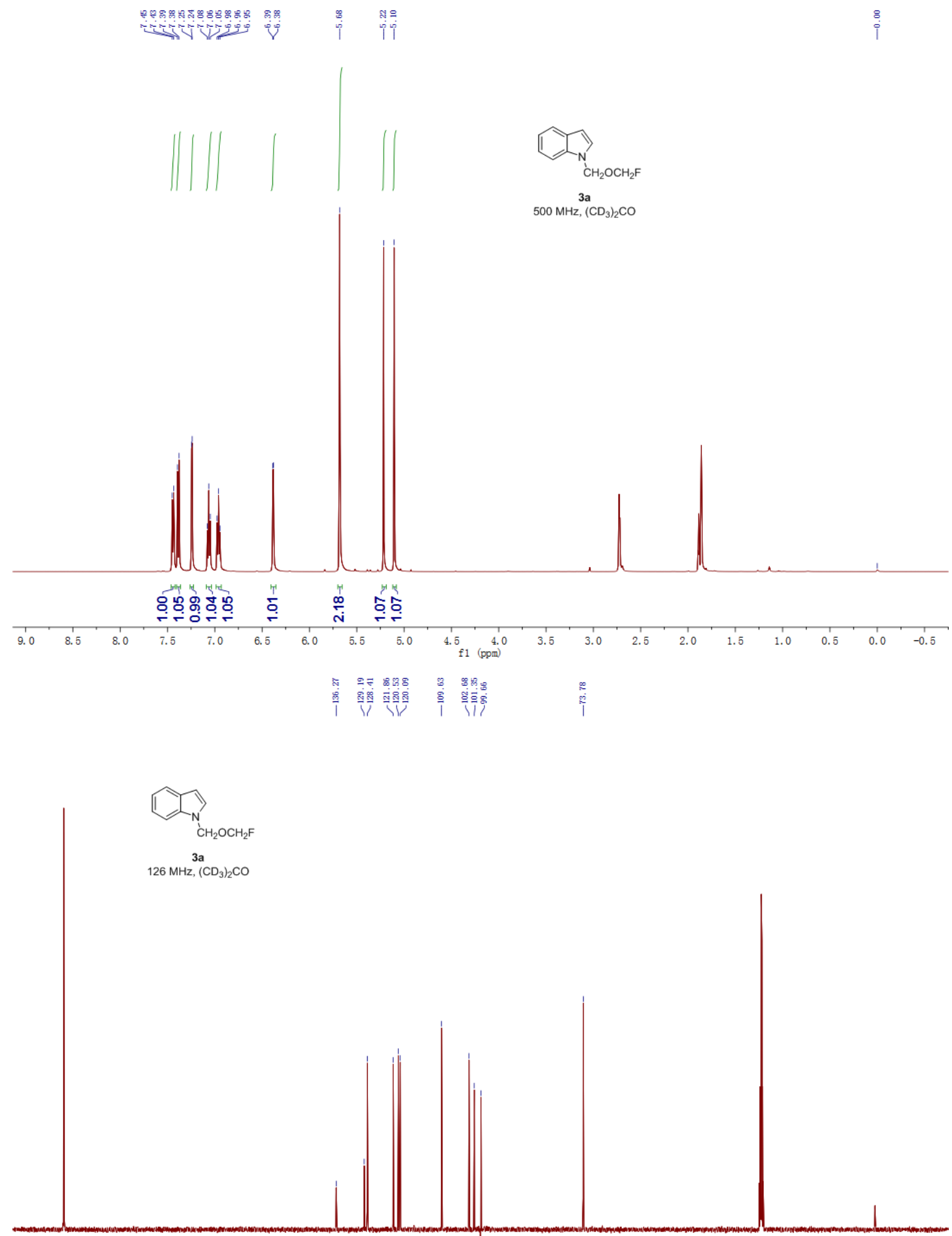

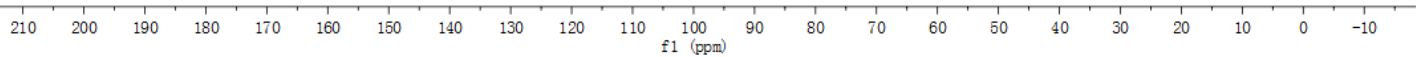




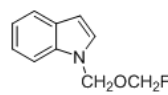

$\mathrm{CH}_{2} \mathrm{OCH}_{2}$

$470 \mathrm{MHz},\left(\mathrm{CD}_{3}\right)_{2} \mathrm{CO}$

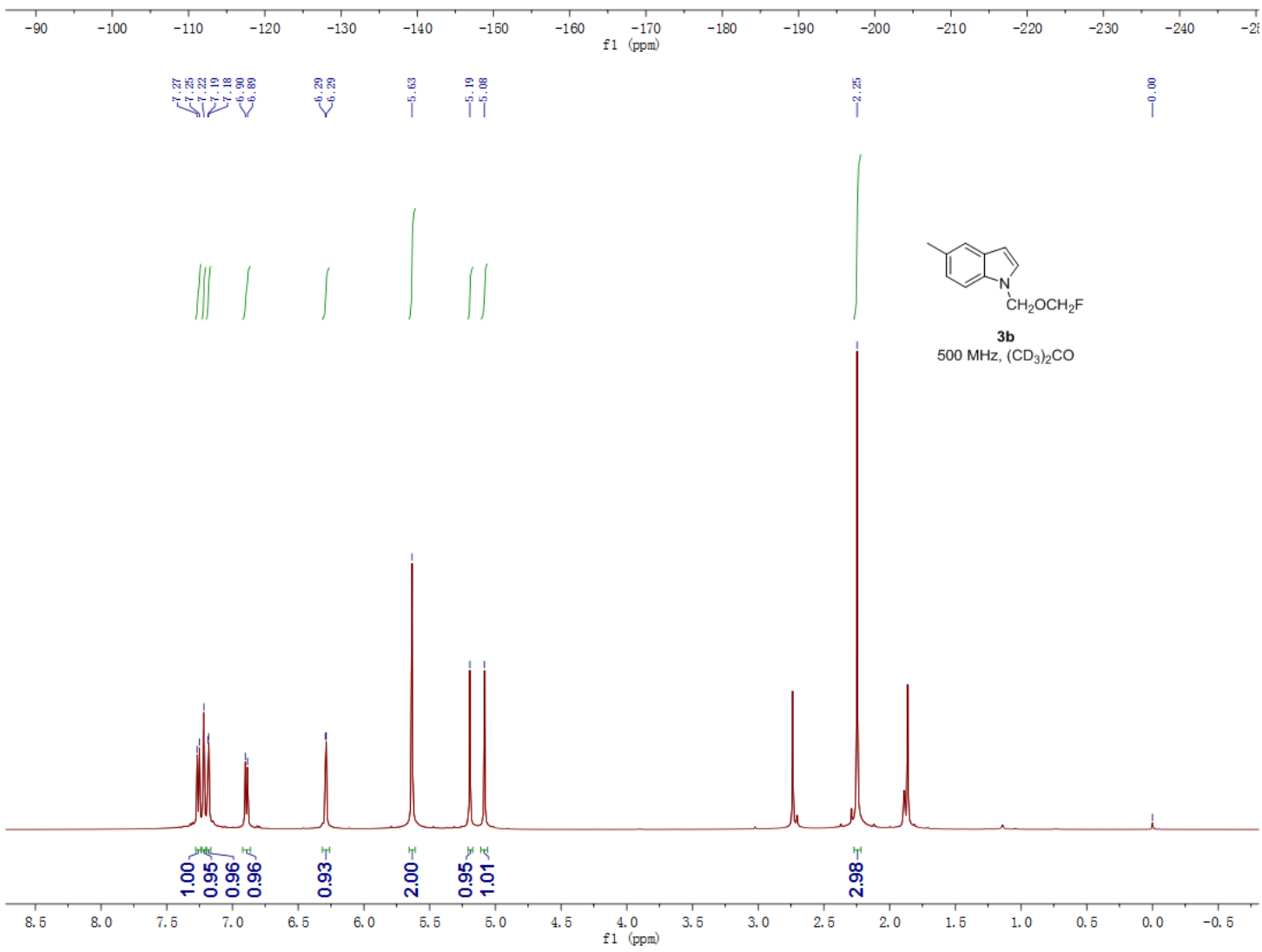




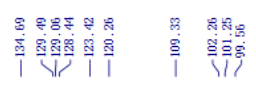

5
1
0

స్.
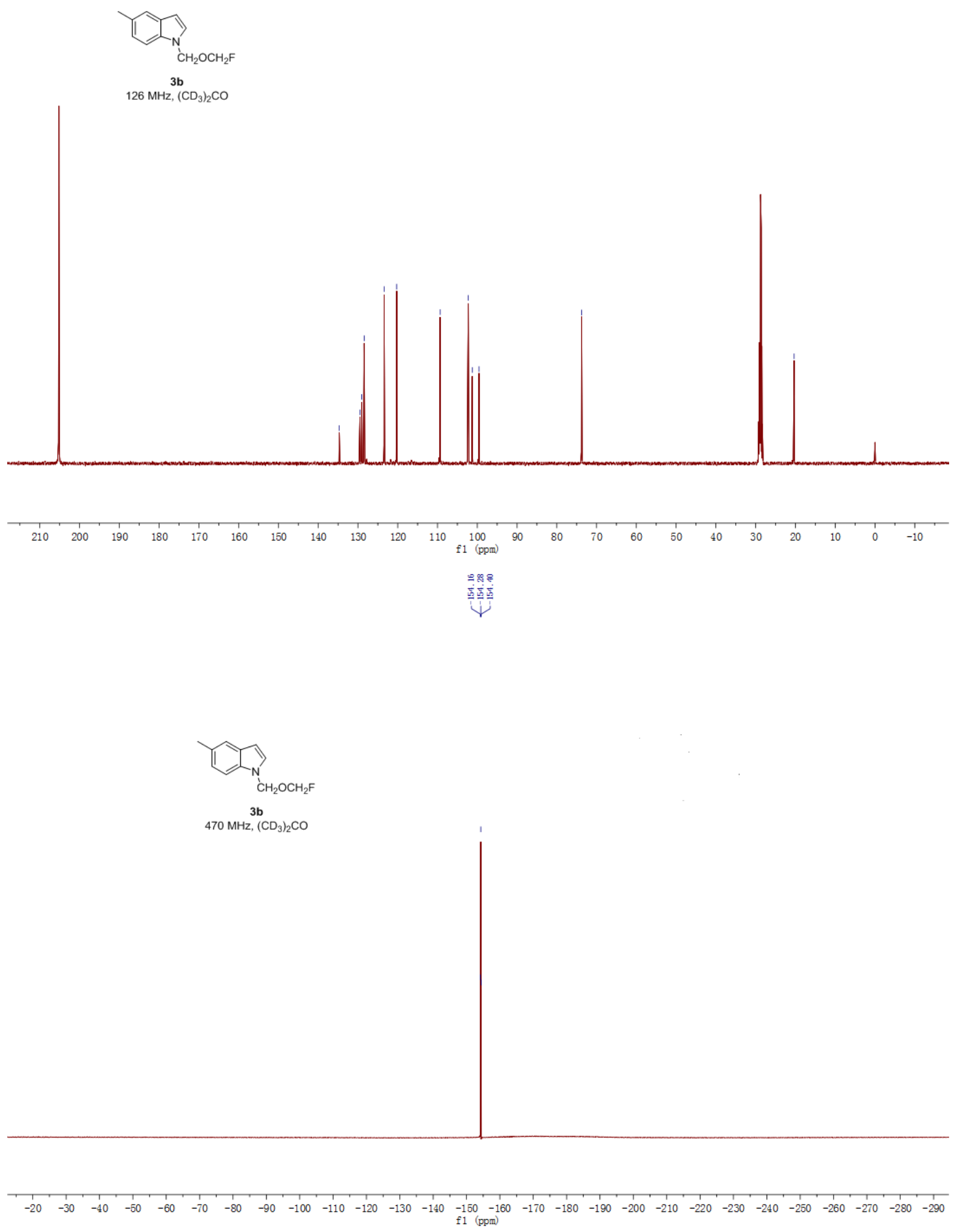

S6 

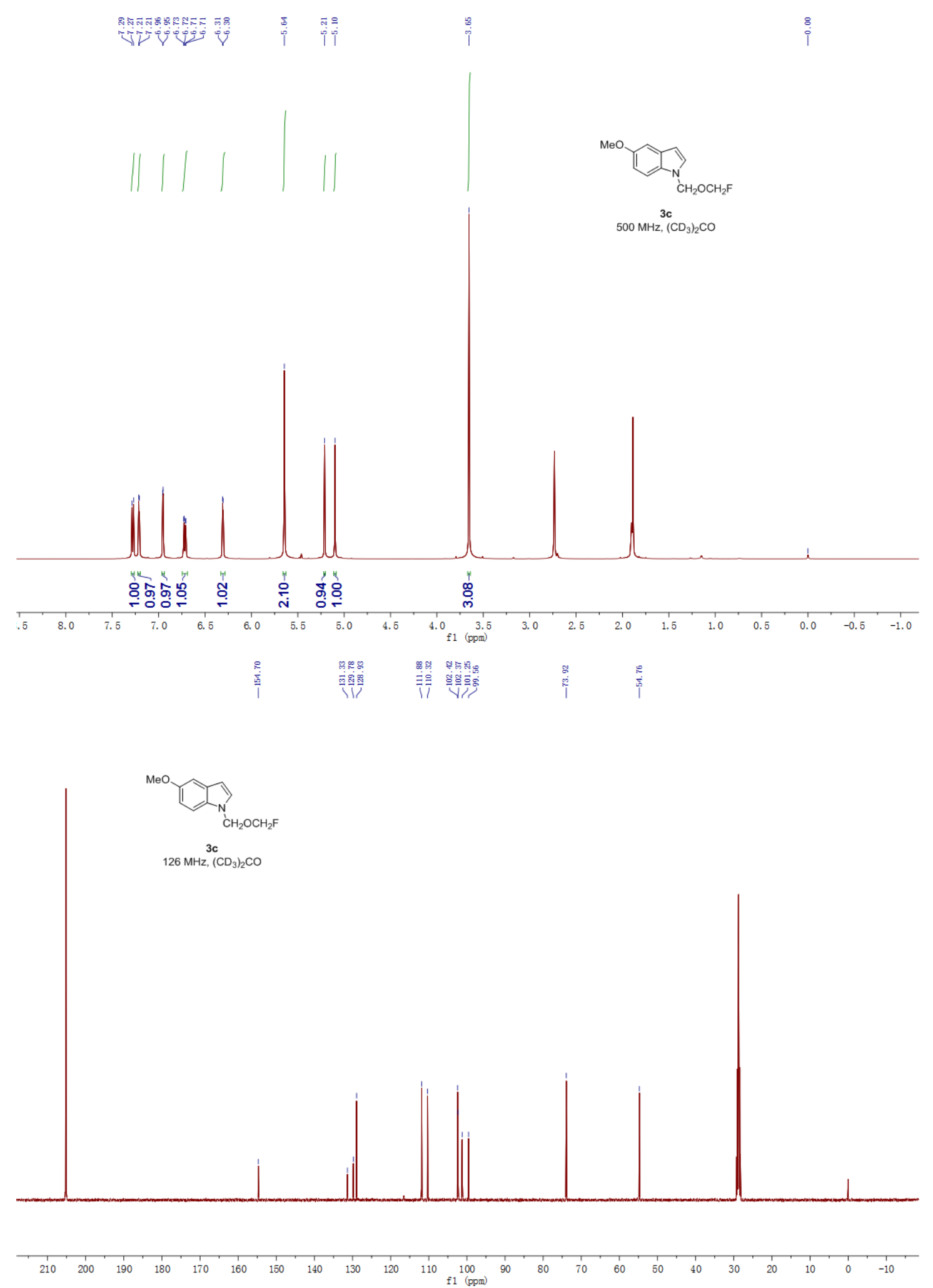

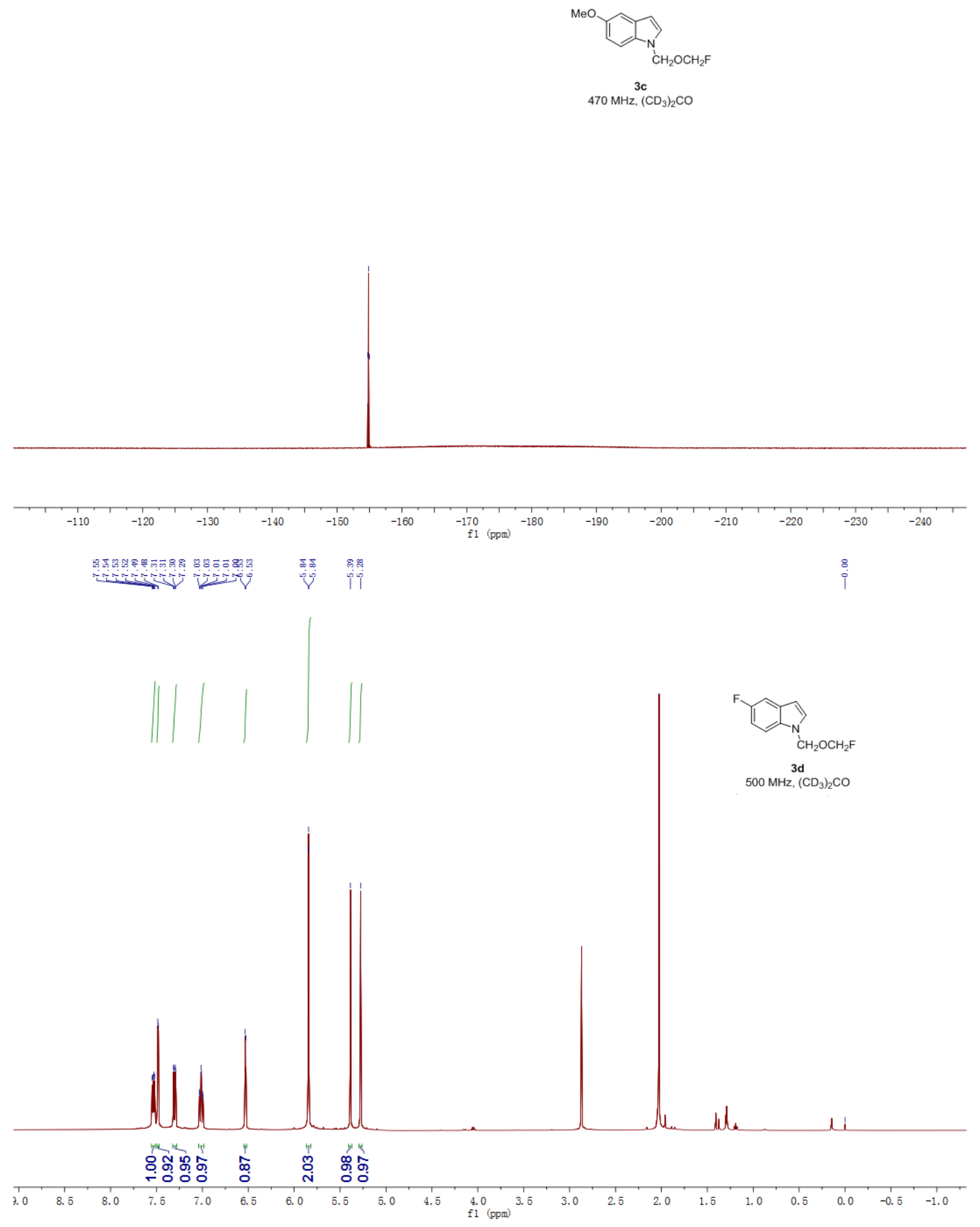


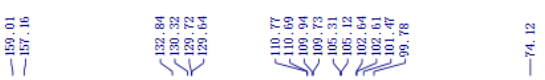
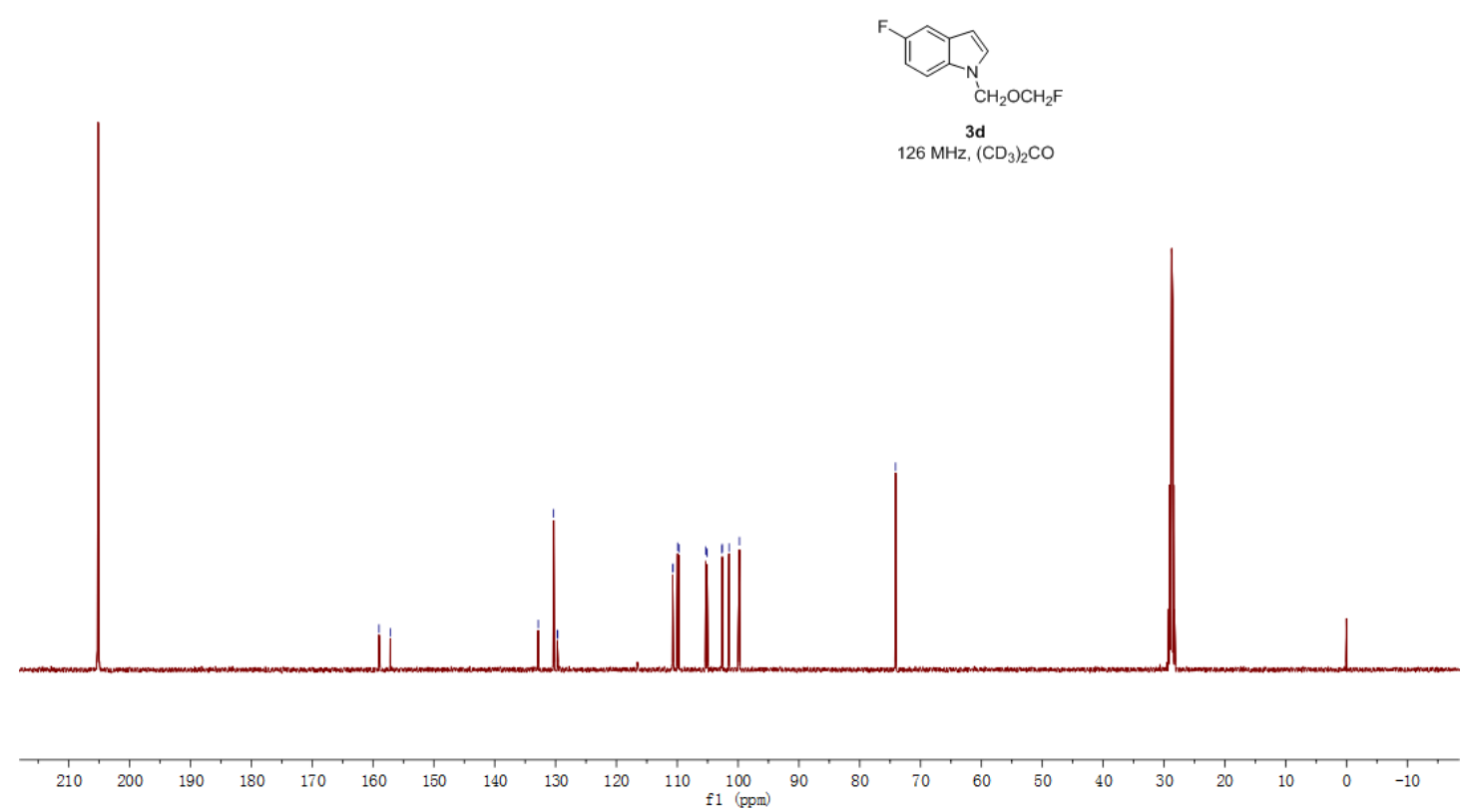

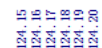

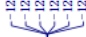

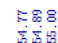

†

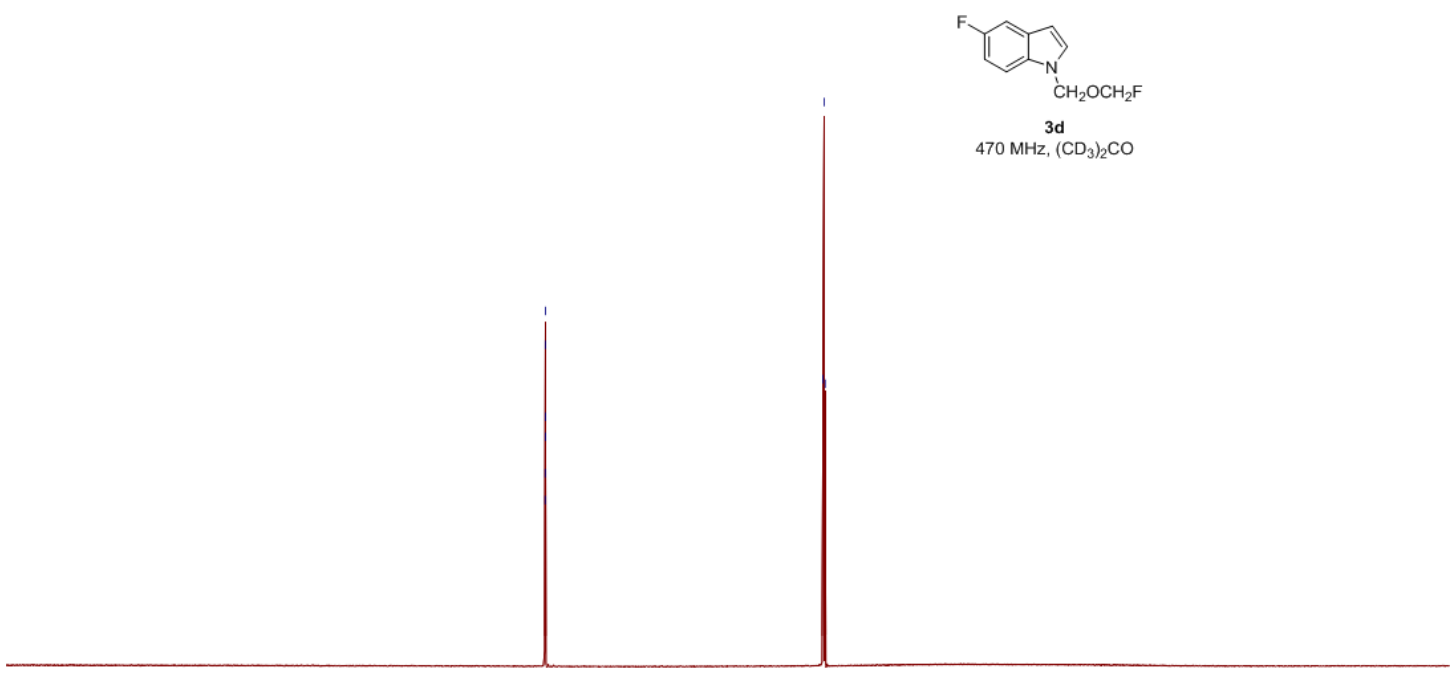

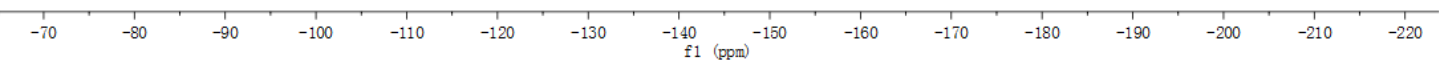




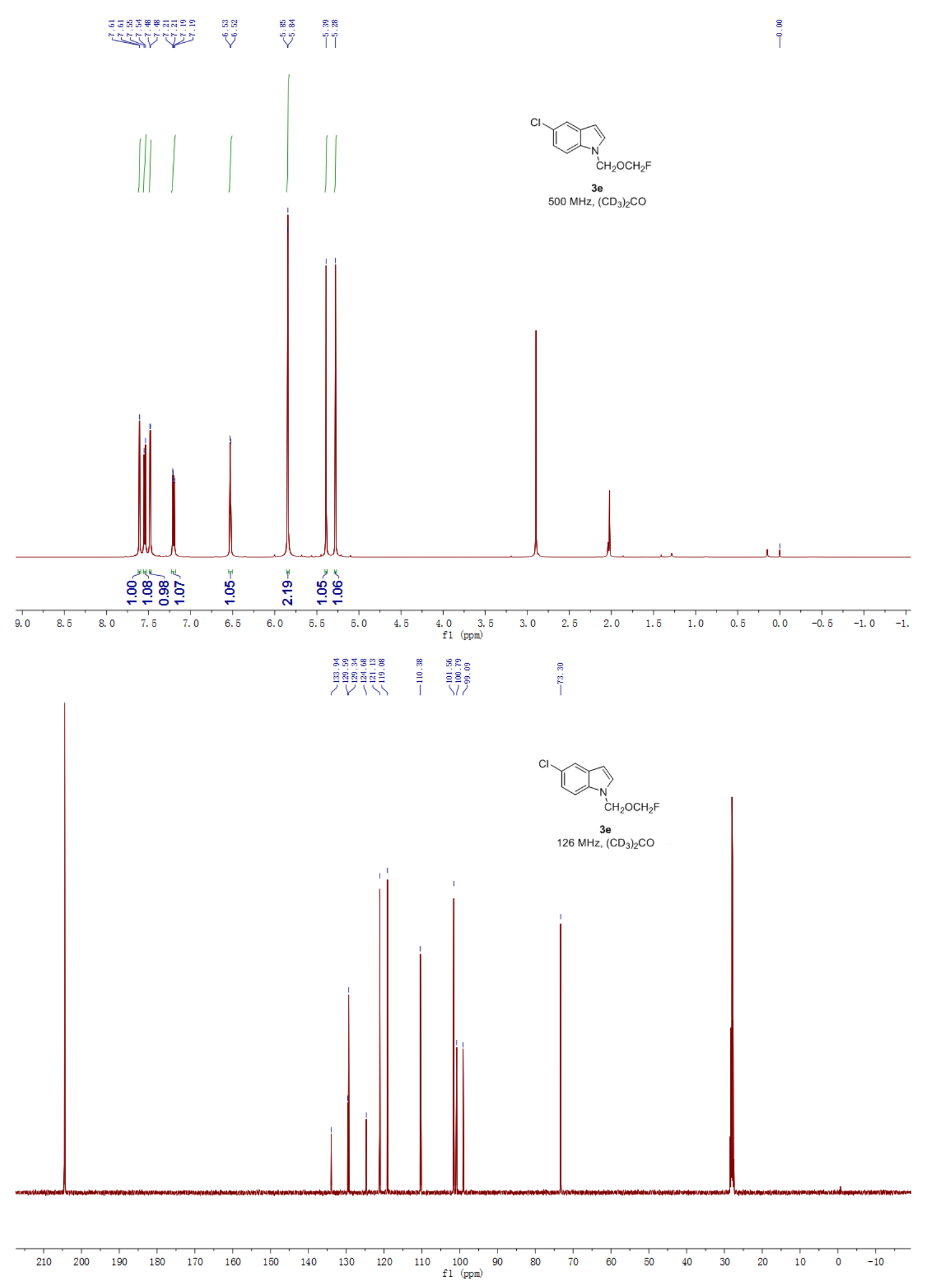




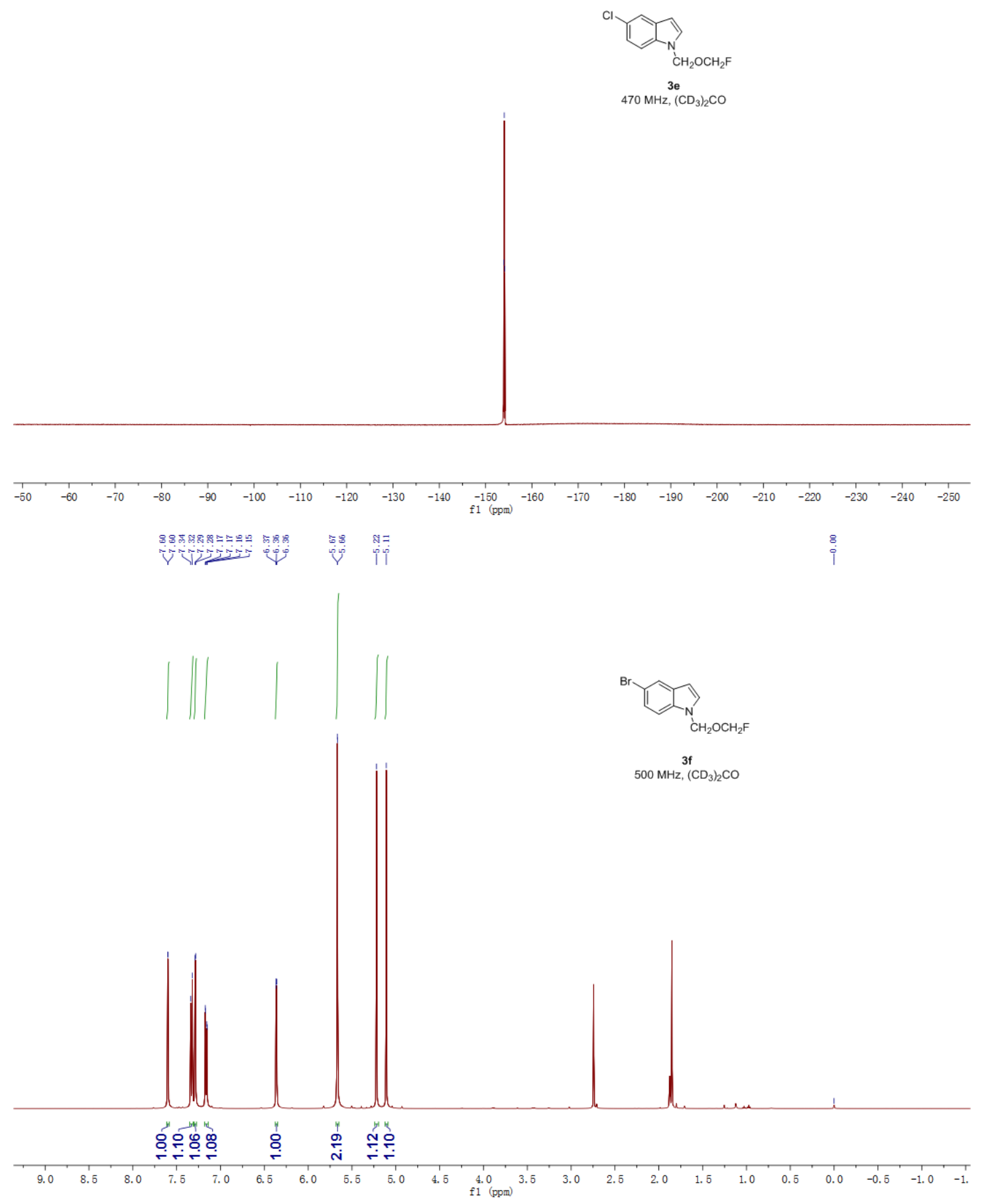




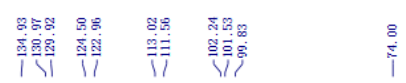
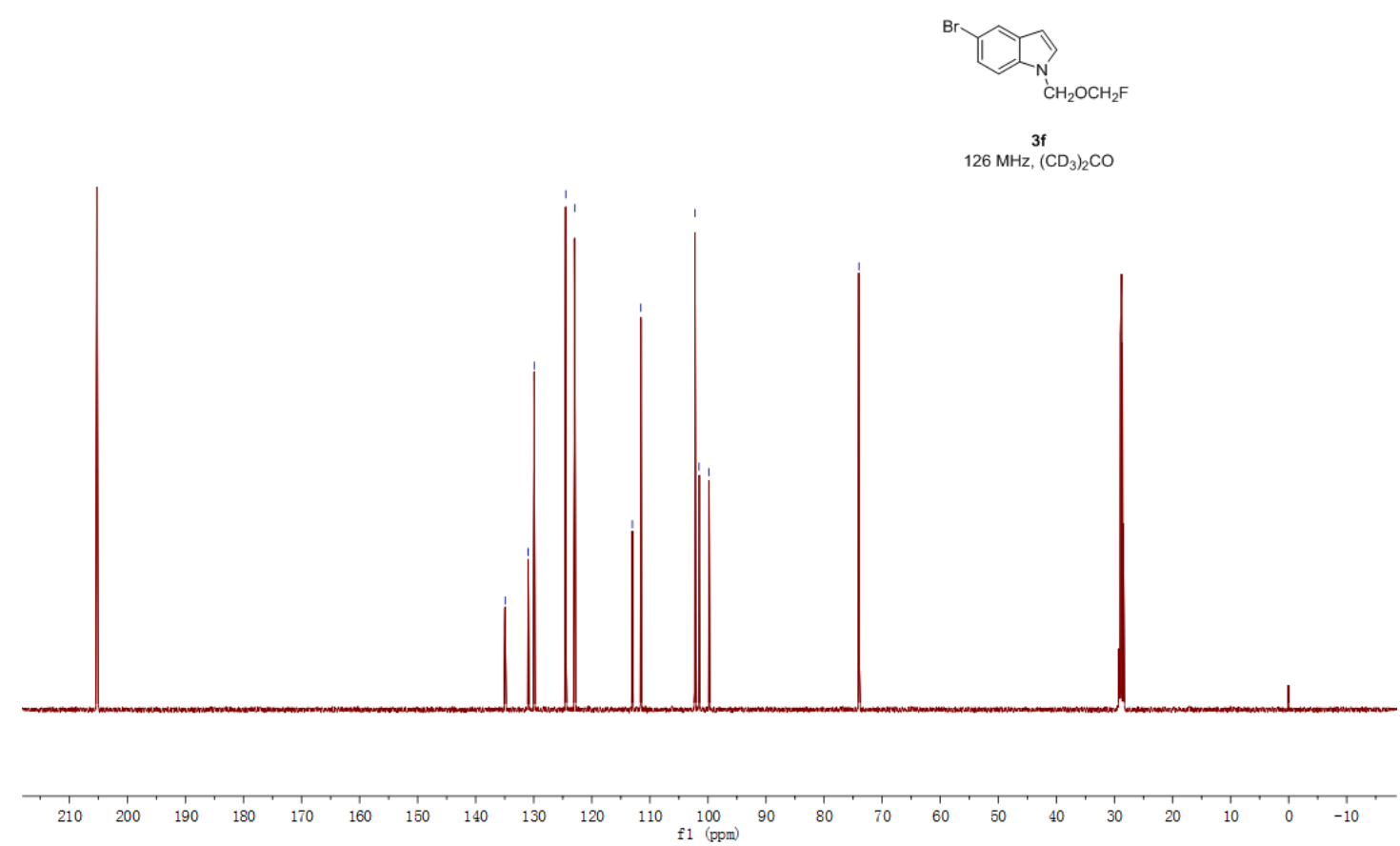

商离部

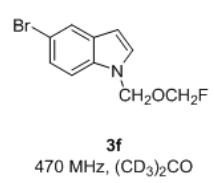

$\begin{array}{lllllllllllllllllllllllllllllll}7 & 1 & -40 & -50 & -60 & -70 & -80 & -90 & -100 & -110 & -120 & -130 & -140 & -150 & -160 & -170 & -180 & -190 & -200 & -210 & -220 & -230 & -240 & -250 & -260 & -270 & -280 & -290\end{array}$ 

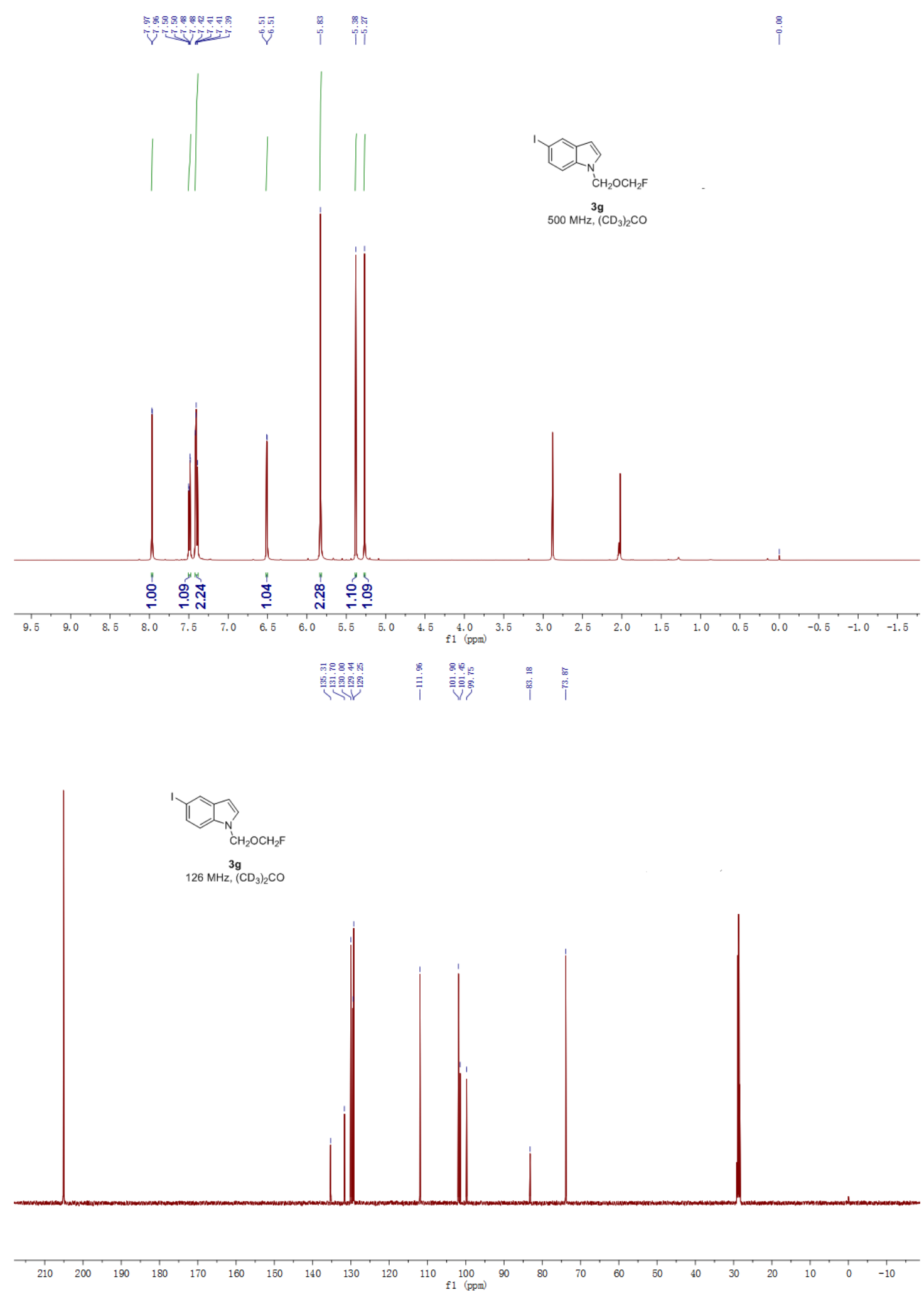

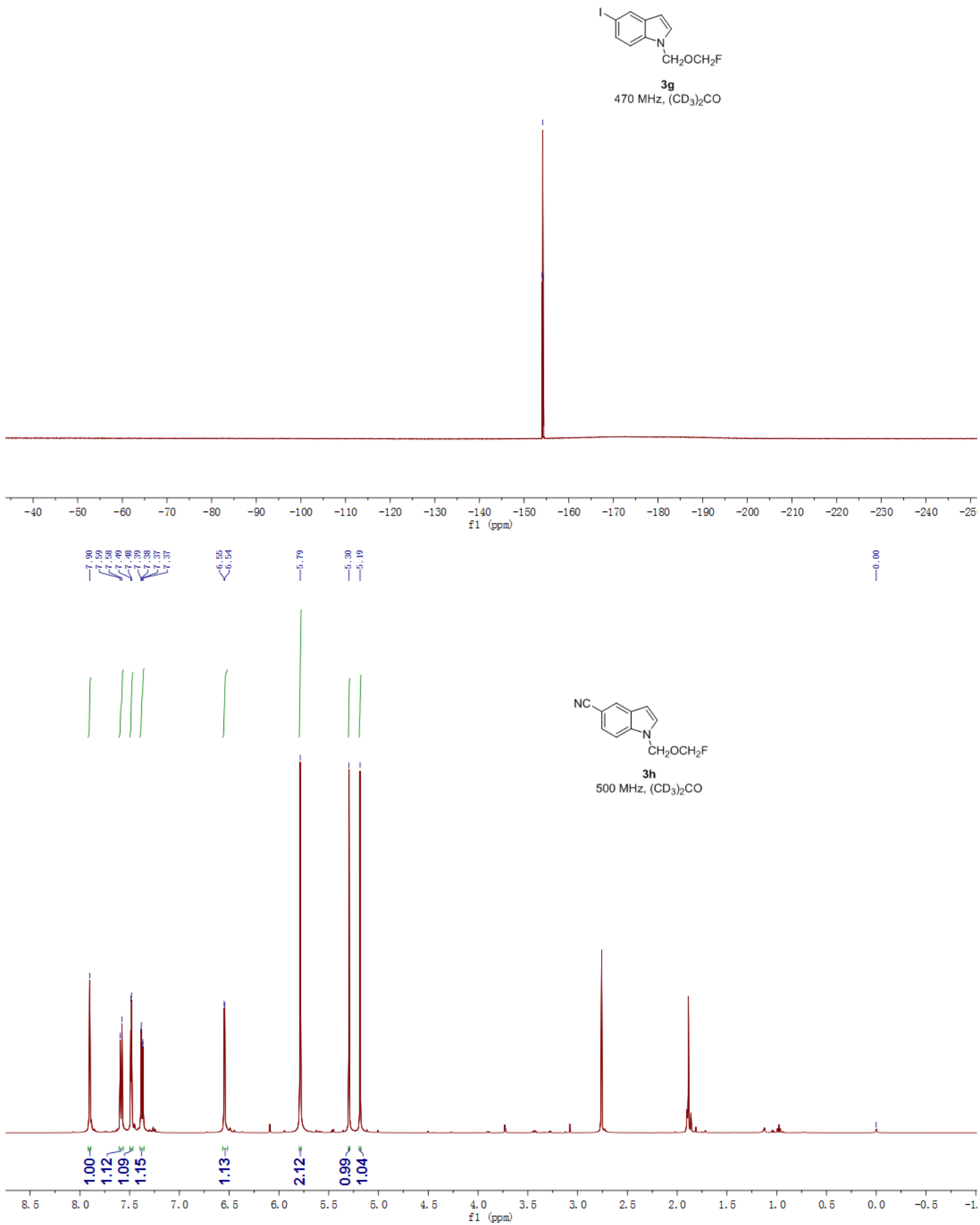


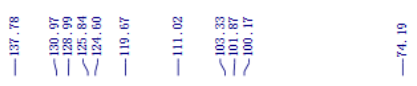

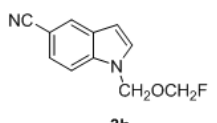

$126 \mathrm{MHz},\left(\mathrm{CD}_{3}\right)_{2} \mathrm{CO}$
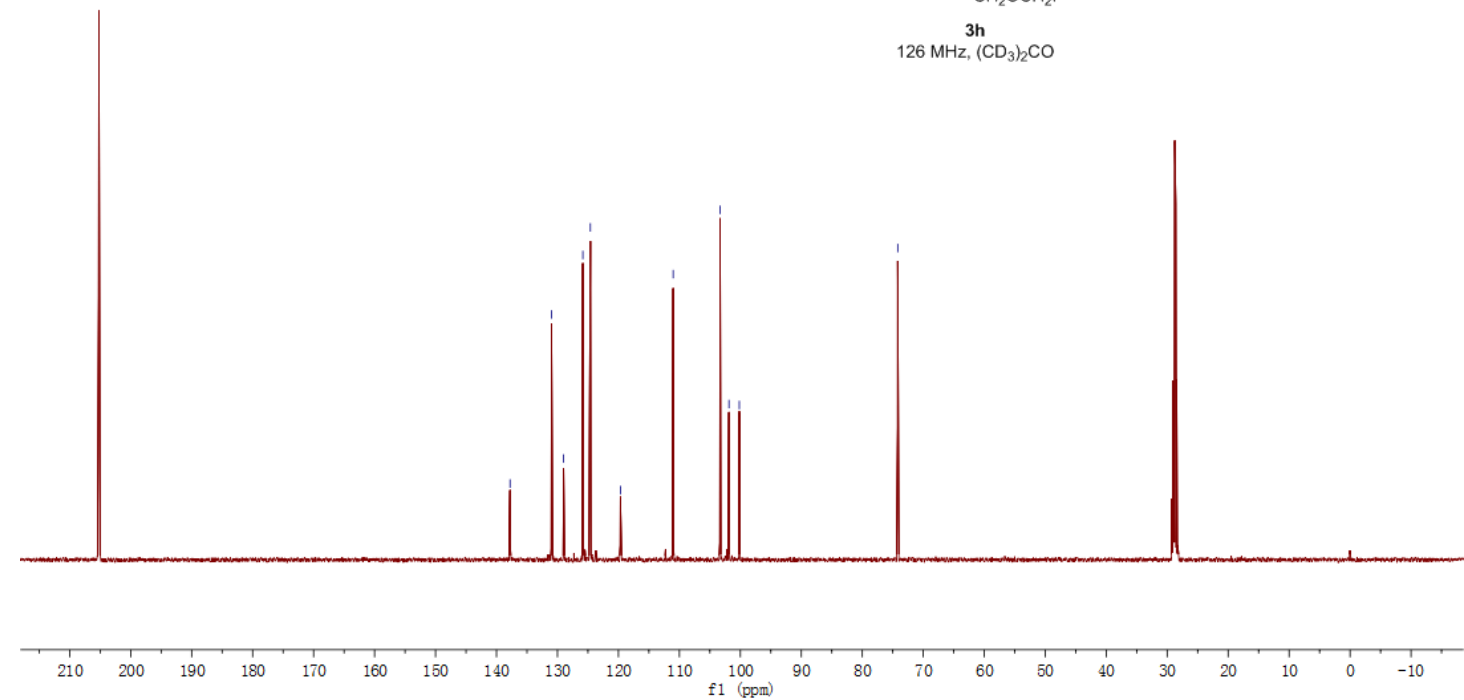

竞离

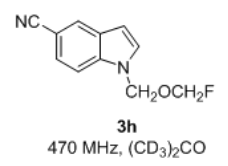

\begin{tabular}{rllllllllllllllllllllllllllllllllllll}
\hline & -10 & -20 & -30 & -40 & -50 & -60 & -70 & -80 & -90 & -100 & -110 & -120 & -130 & -140 & -150 & -160 & -170 & -180 & -190 & -200 & -210 & -220 & -230 & -240 & -250 & -260 & -270 & -280
\end{tabular} 


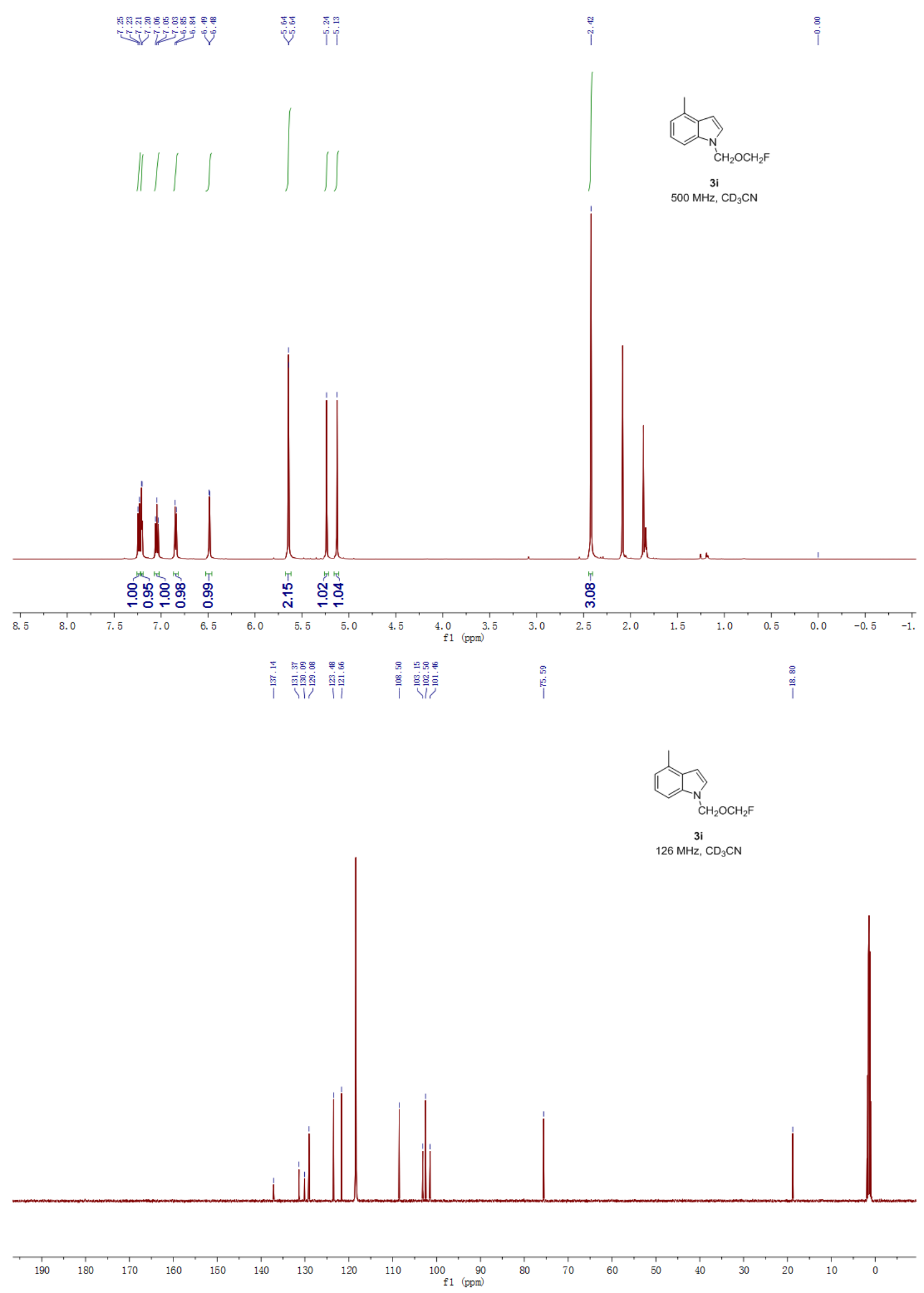



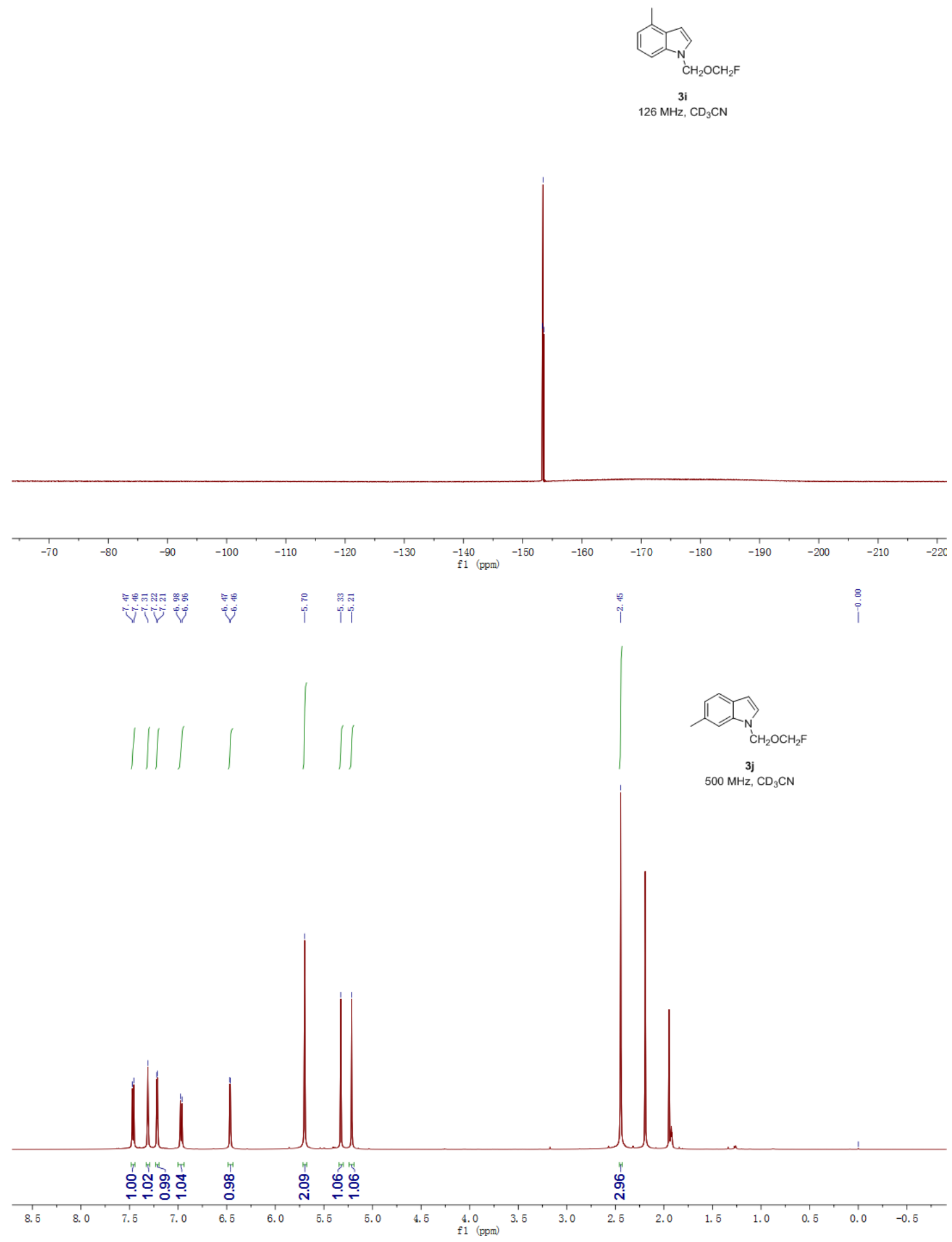
क 99

|

$\underset{\substack{F \\ i}}{\substack{i \\ i}}$

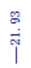
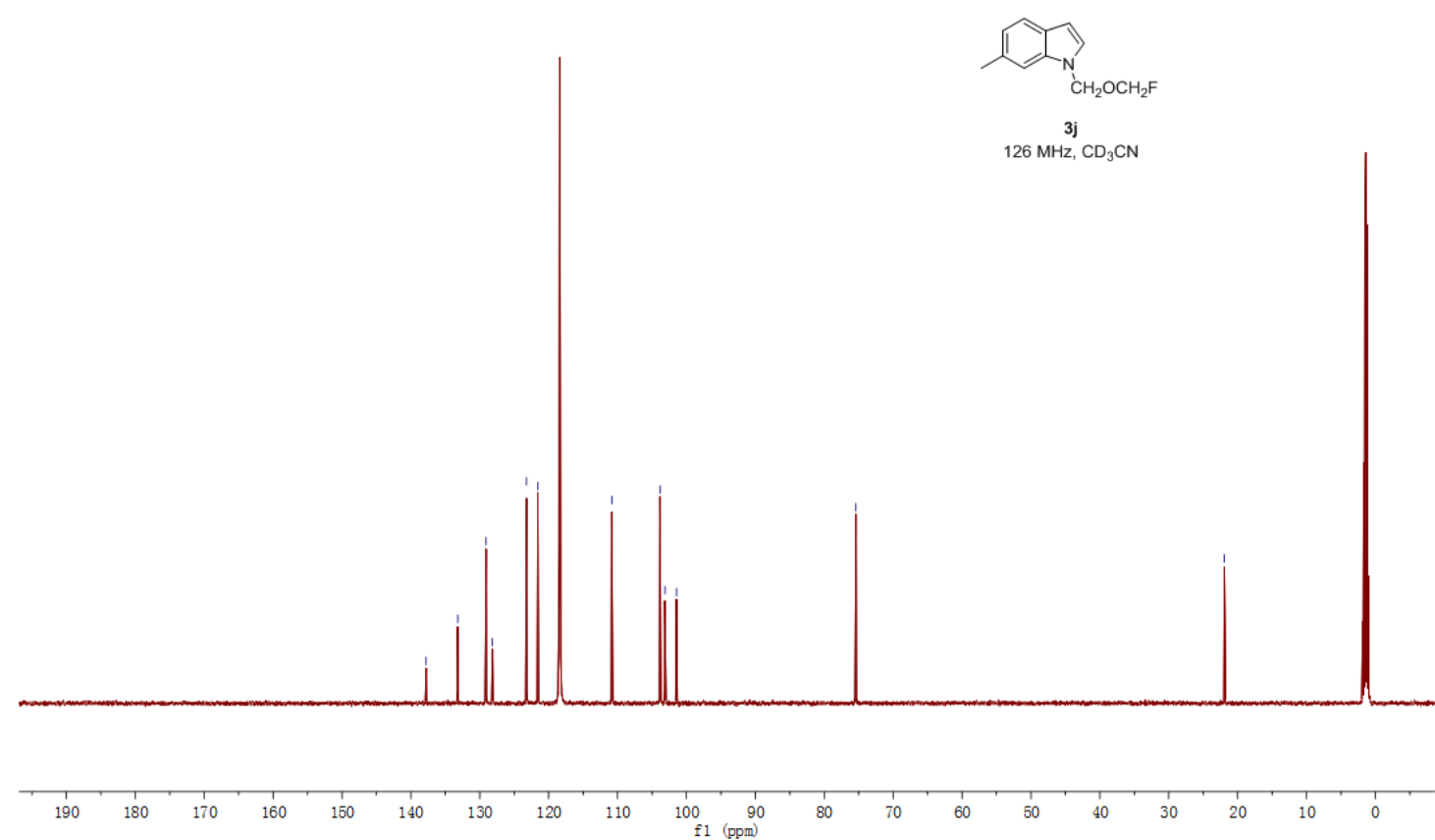

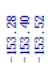

证

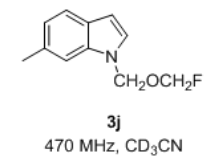

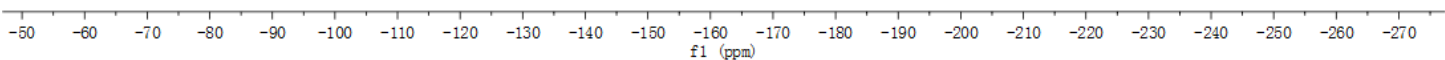




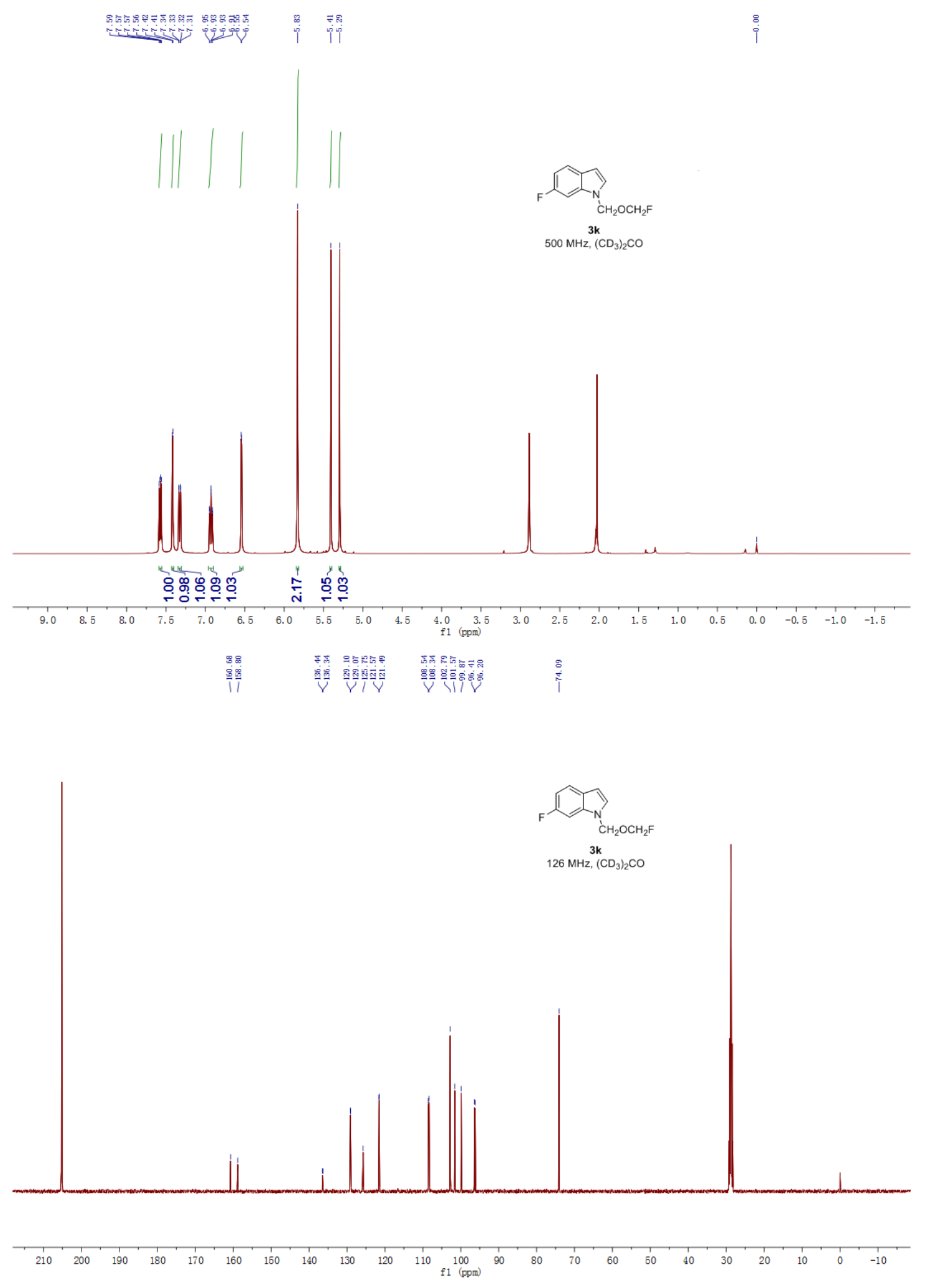




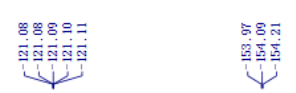
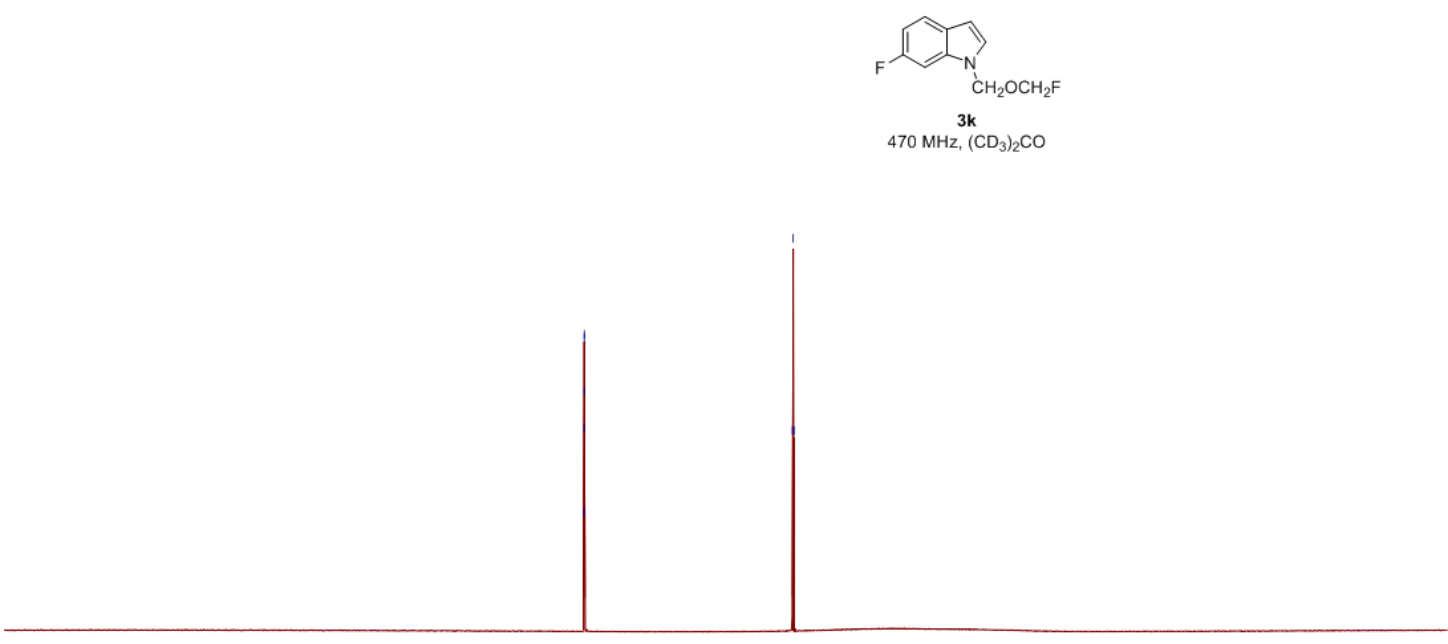

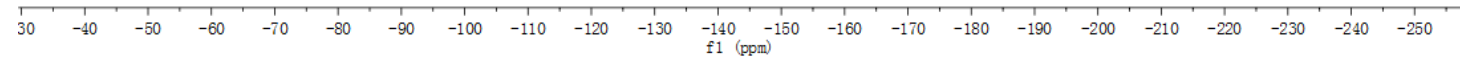

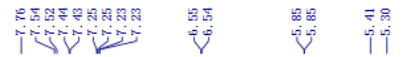

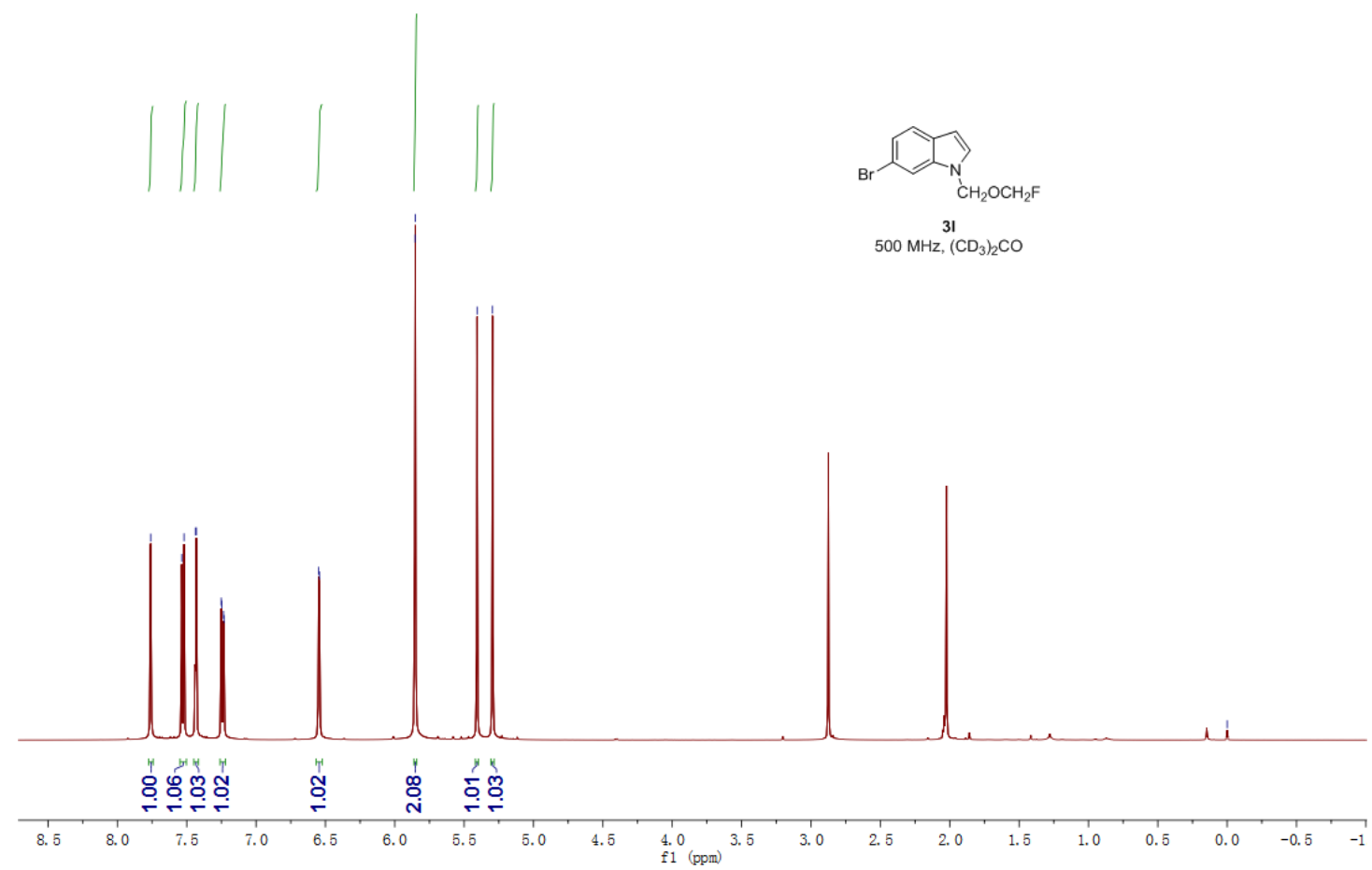




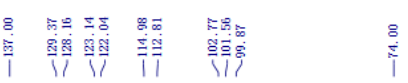
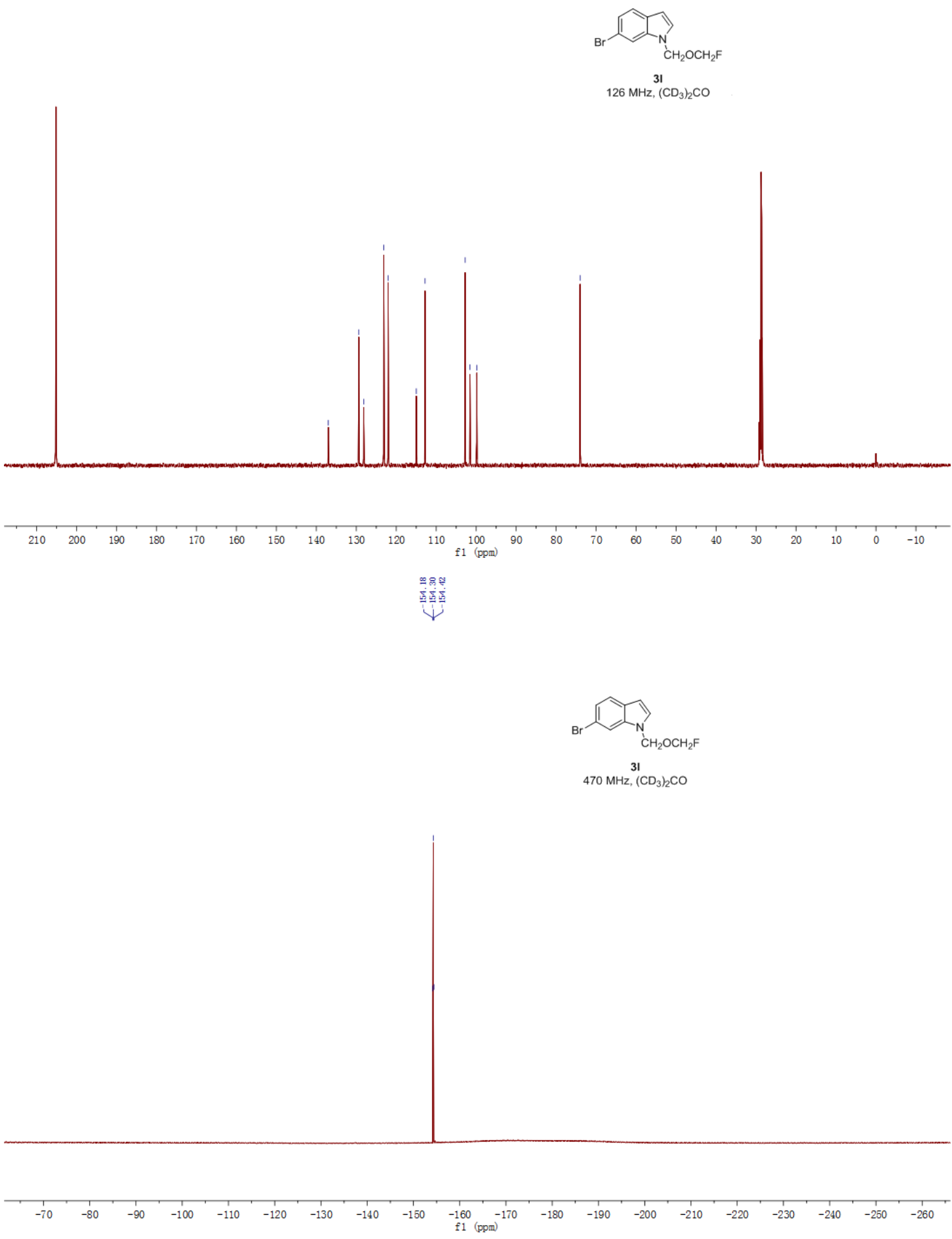


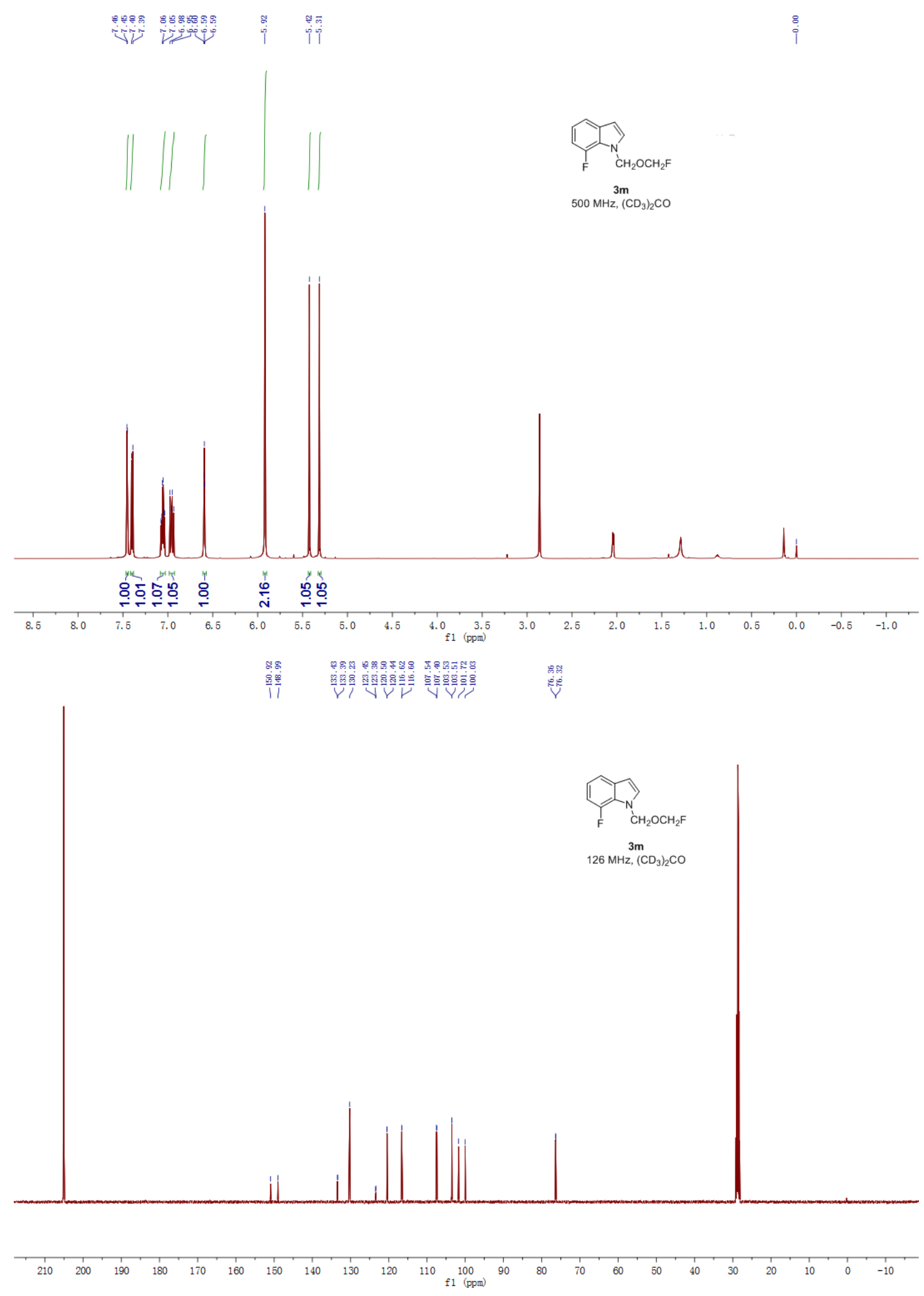



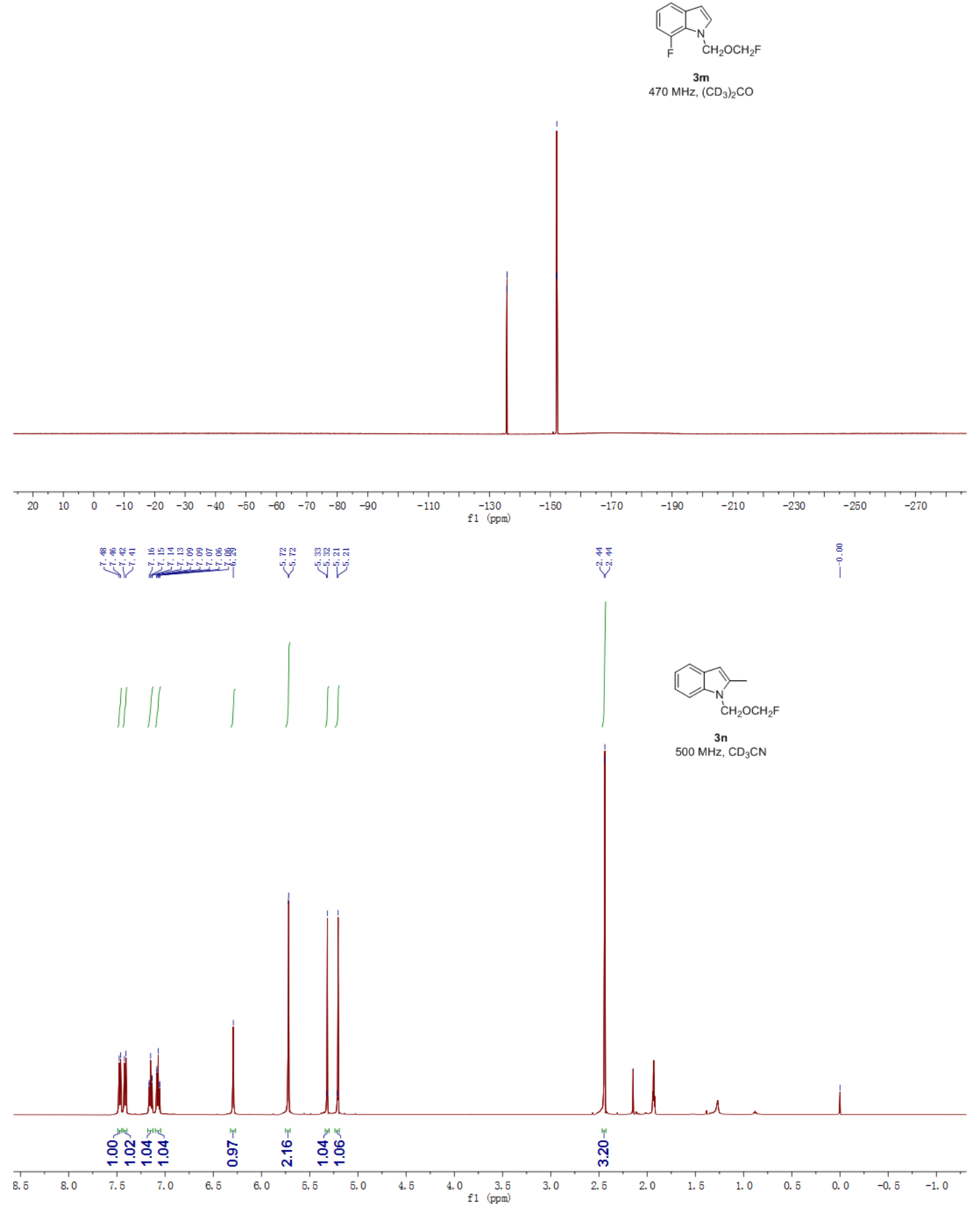

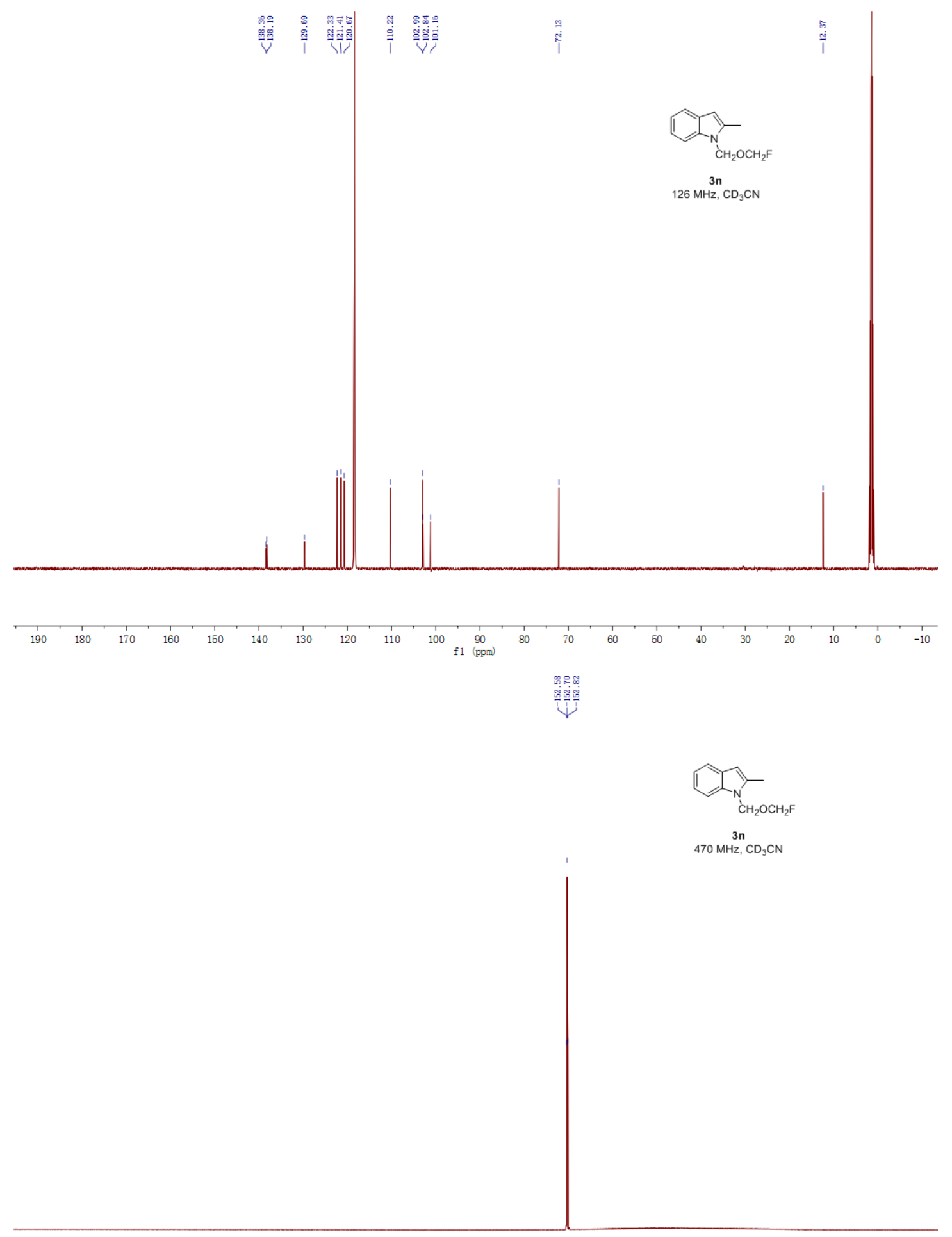

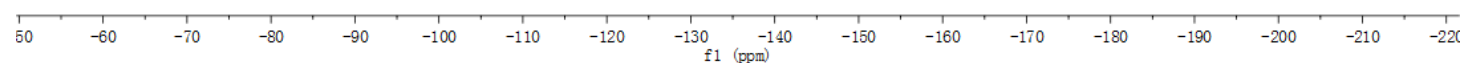




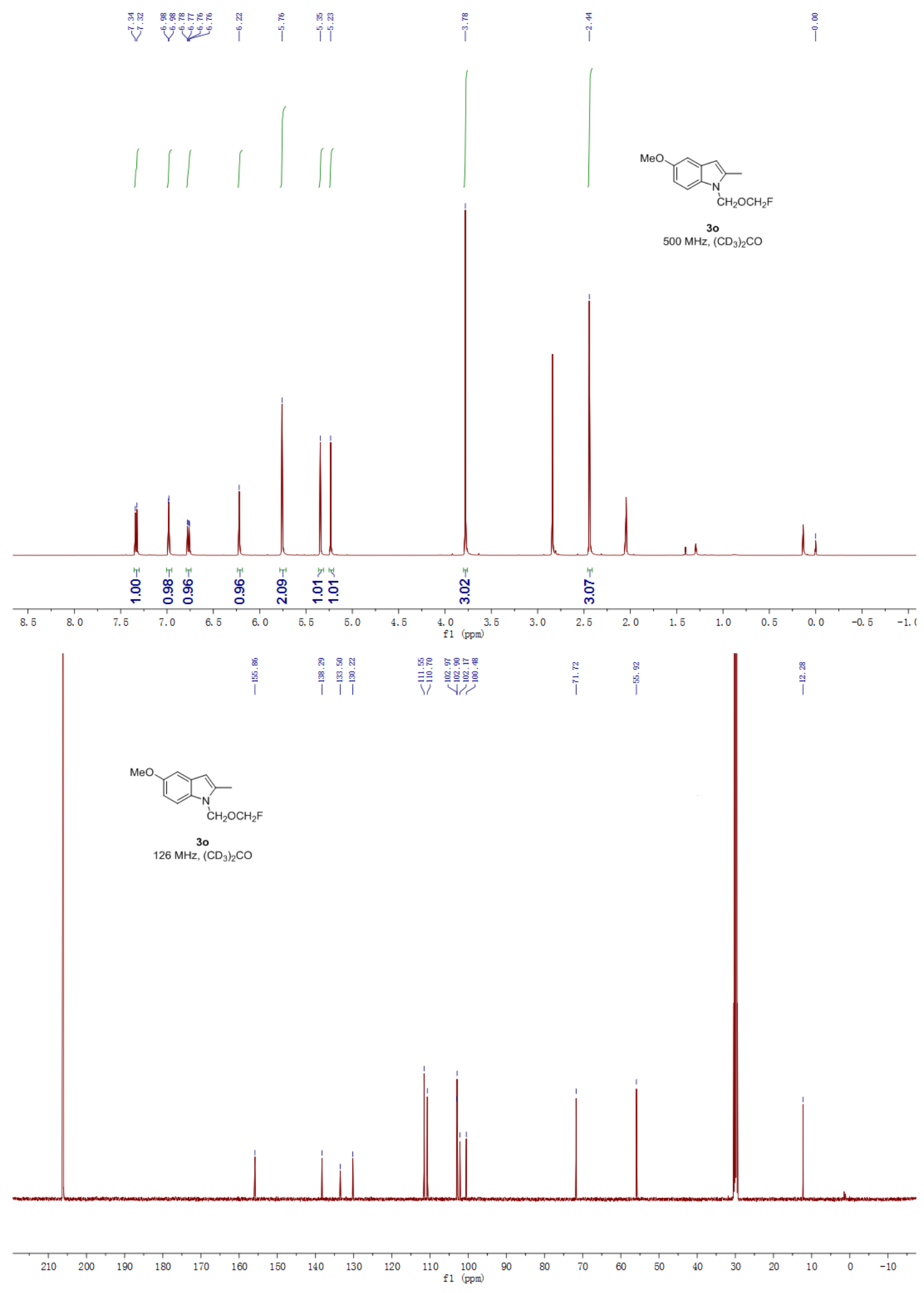



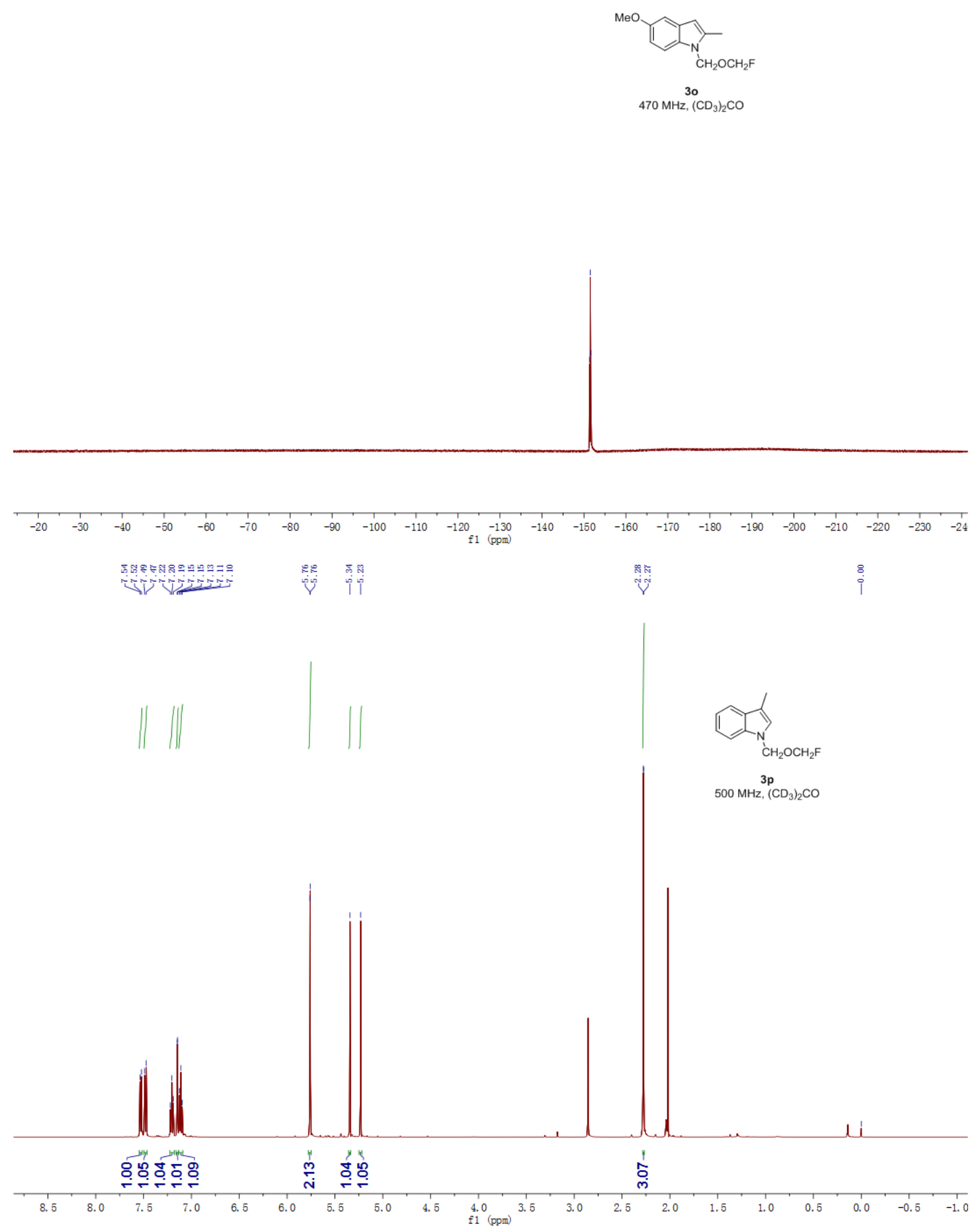

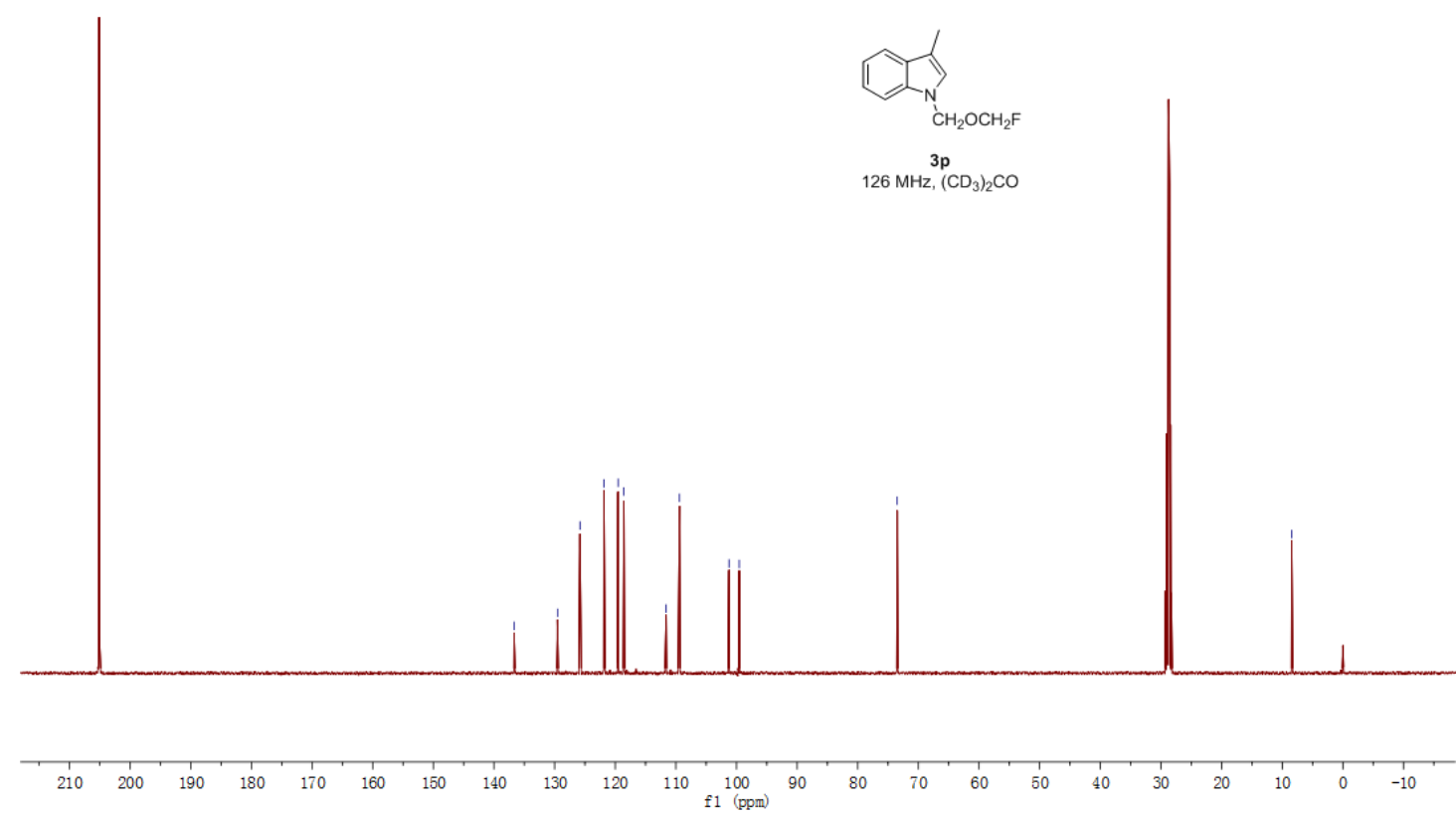
产望定

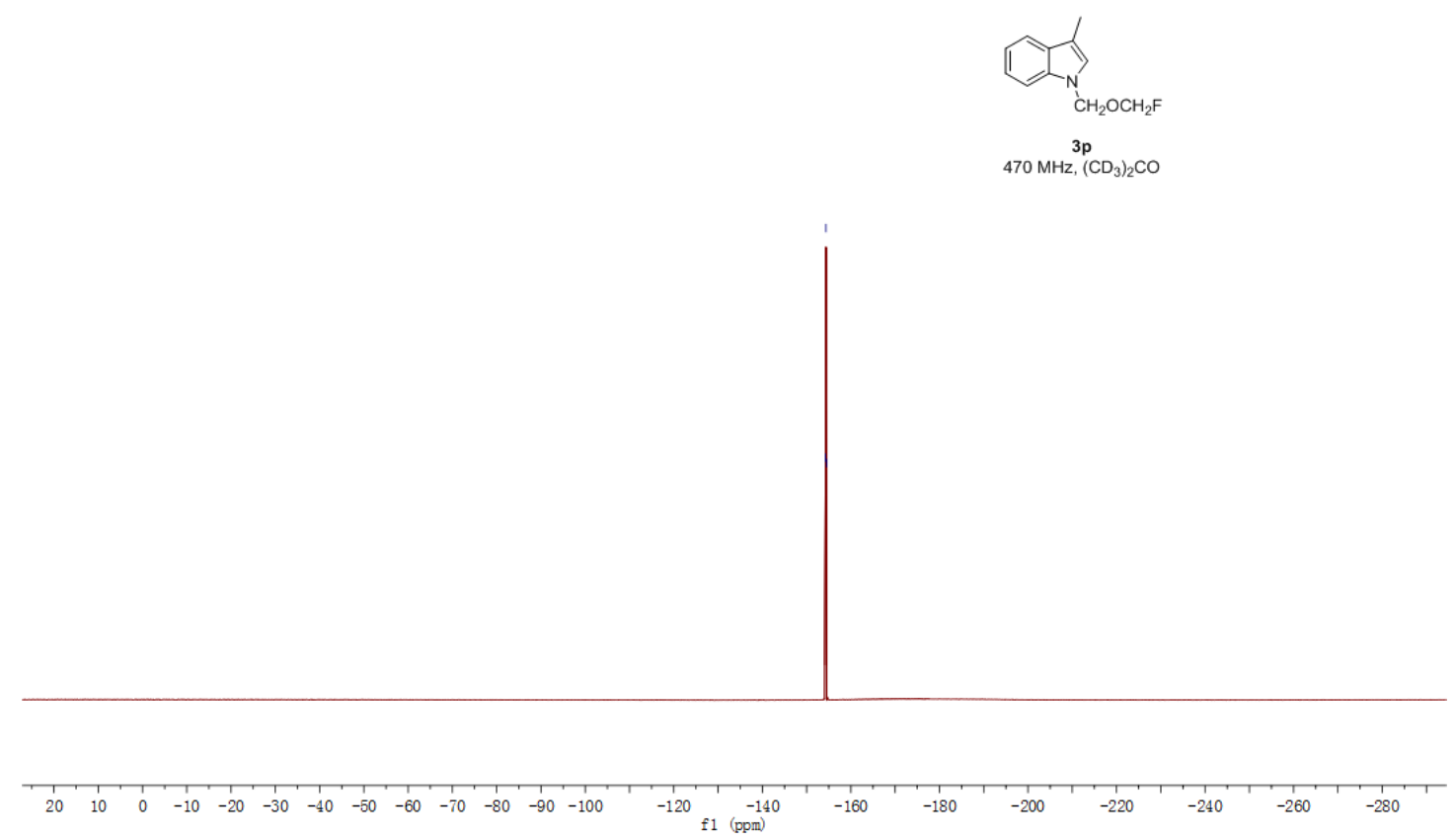



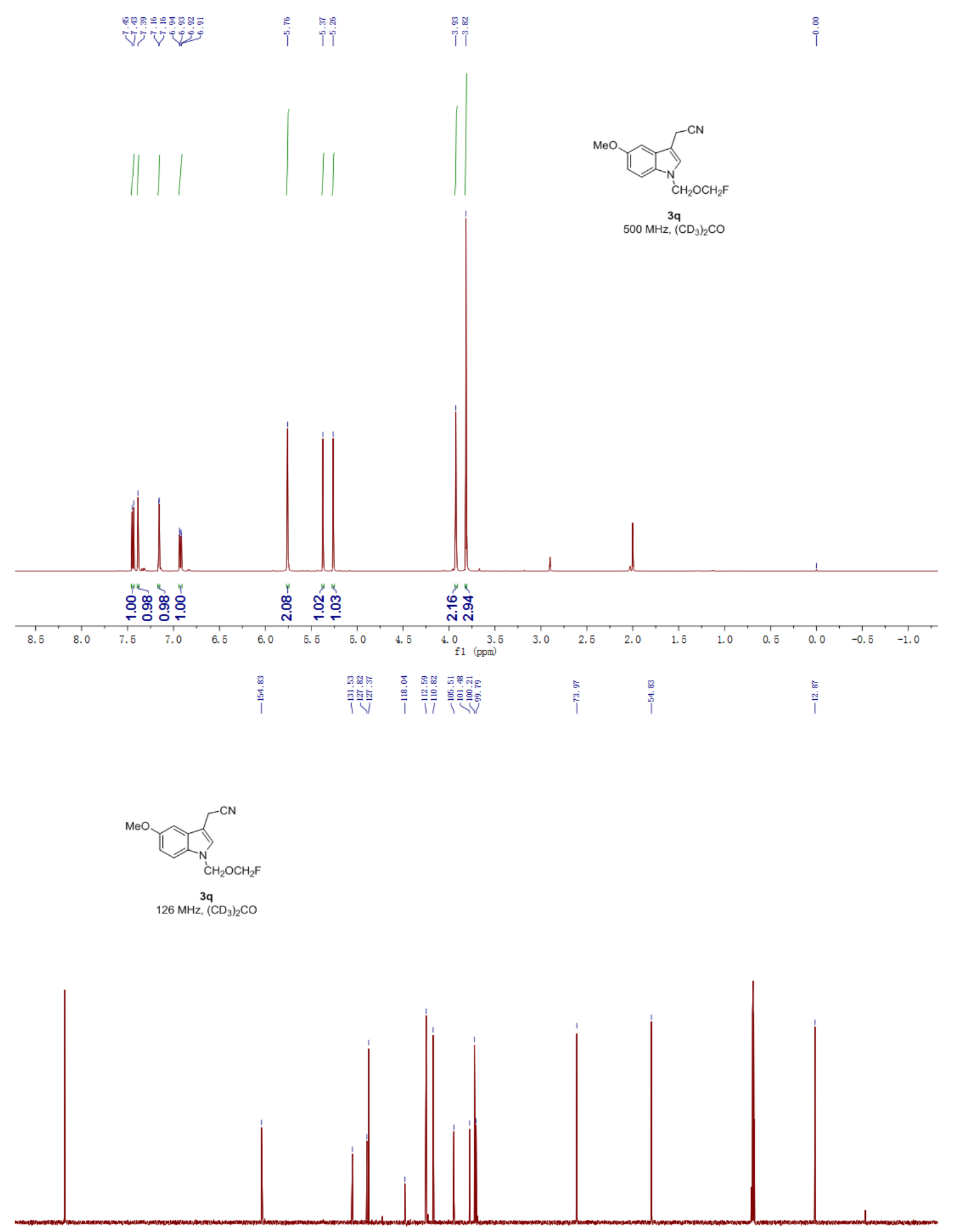

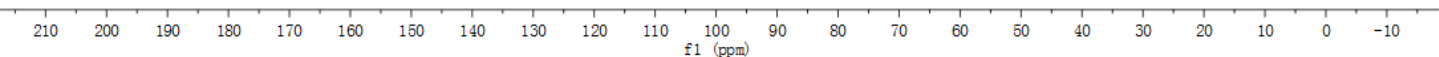



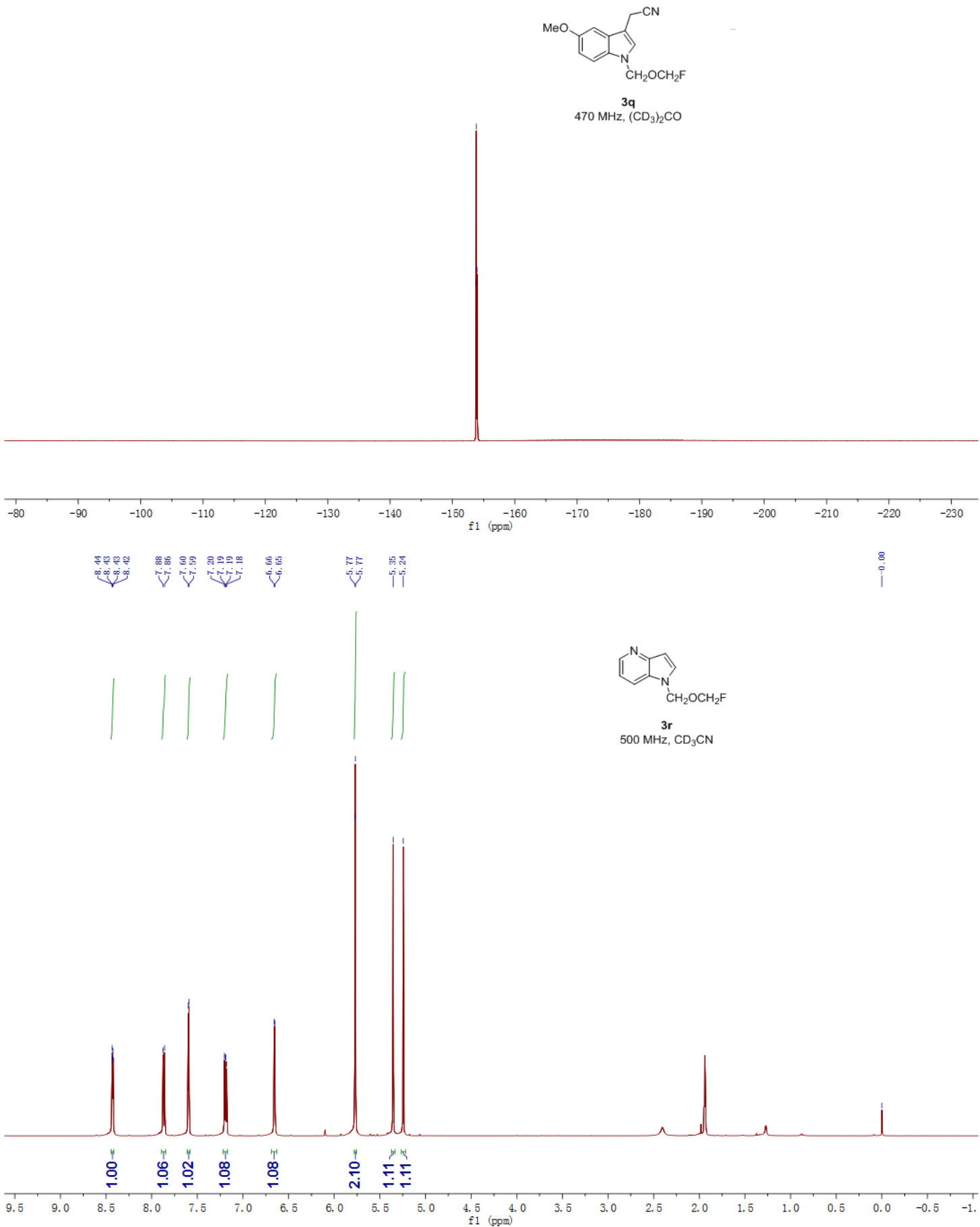

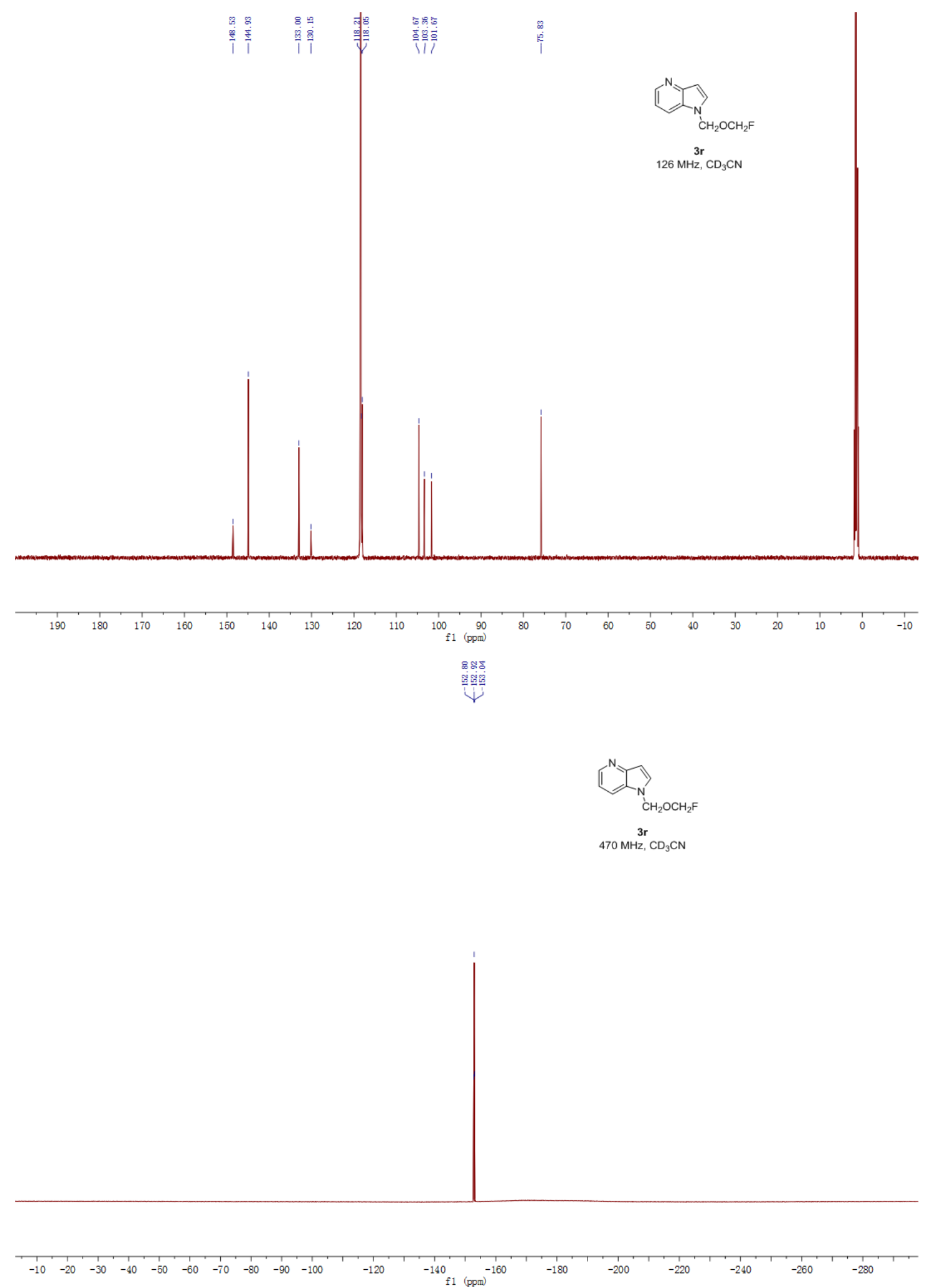


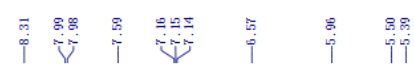

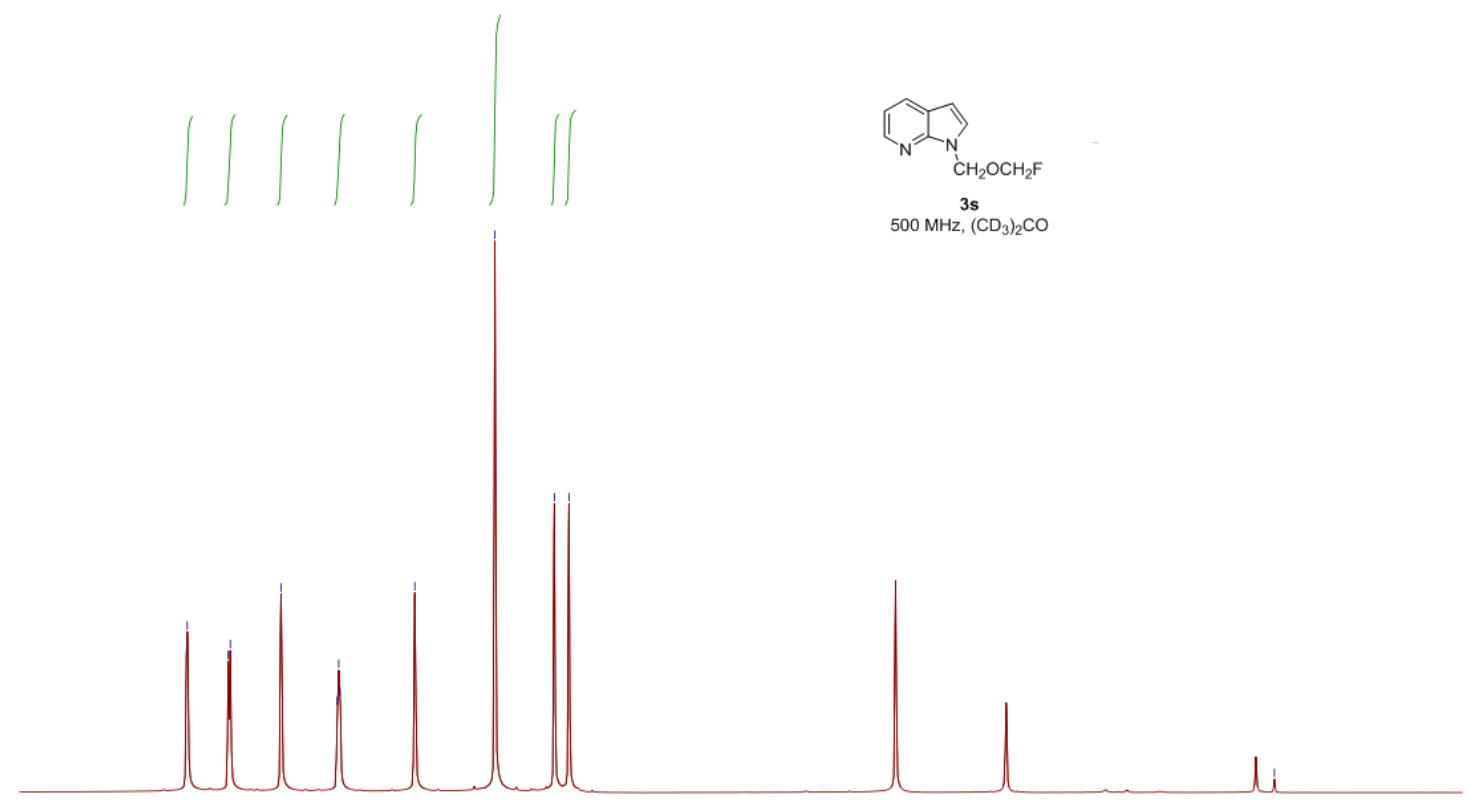

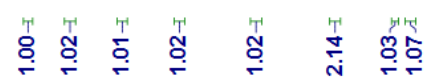

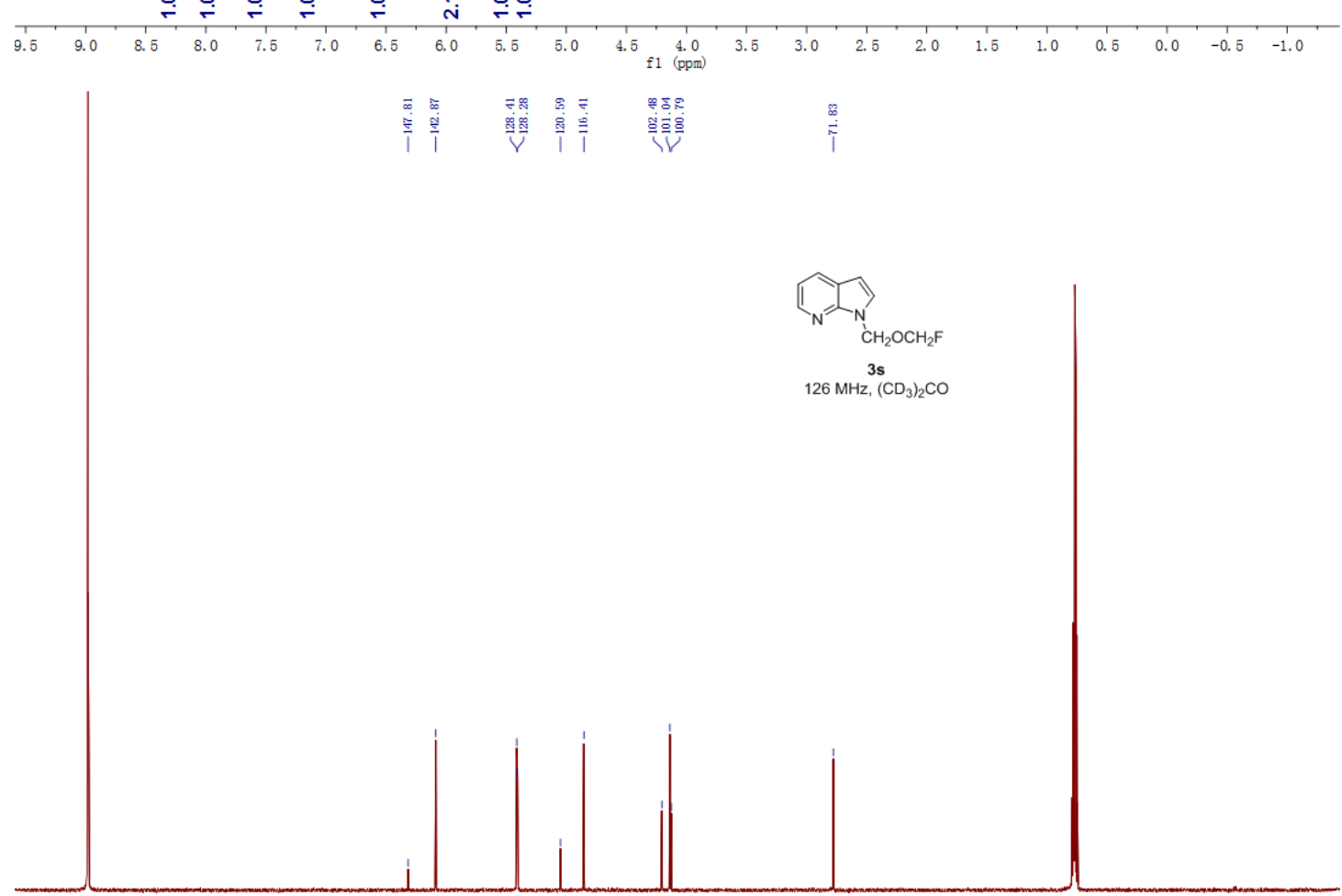

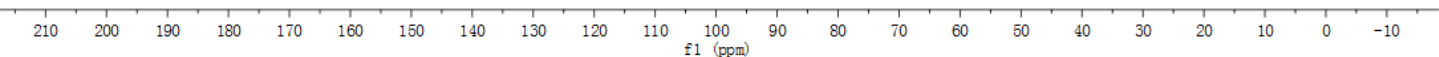




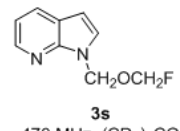

$470 \mathrm{MHz},\left(\mathrm{CD}_{3}\right)_{2} \mathrm{CO}$
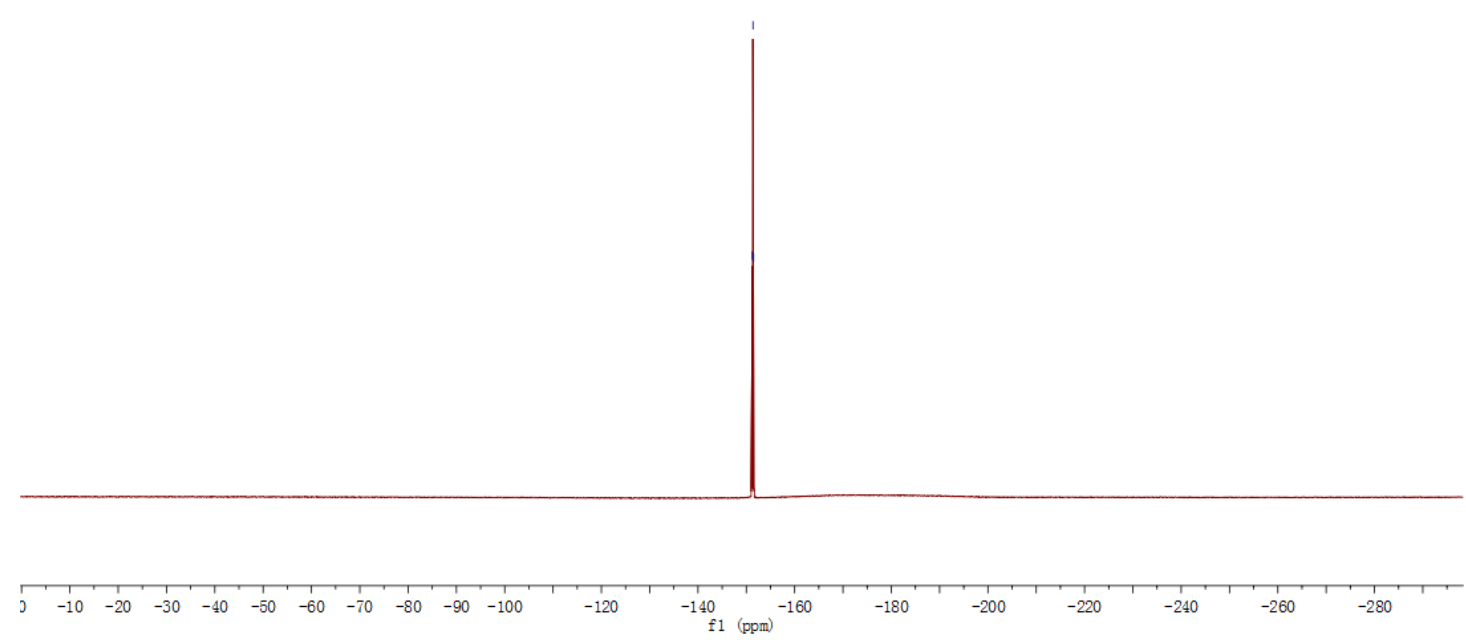

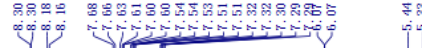
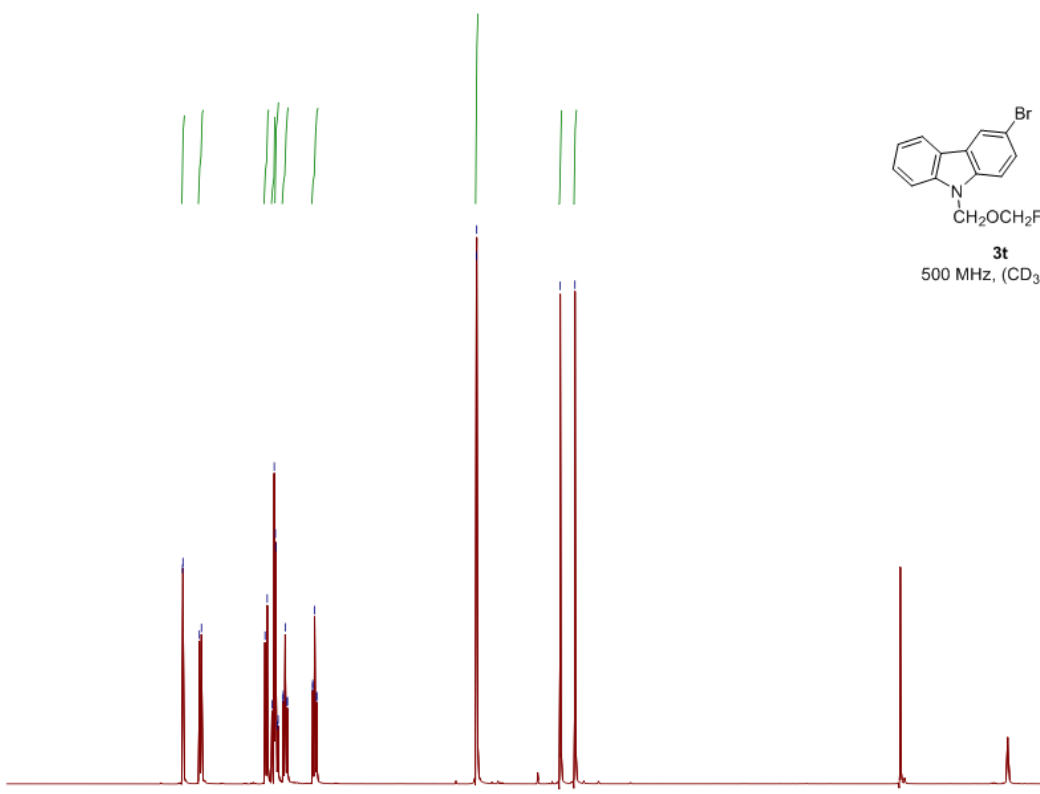

$500 \mathrm{MHz},\left(\mathrm{CD}_{3}\right)_{2} \mathrm{CO}$

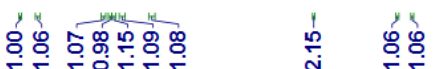

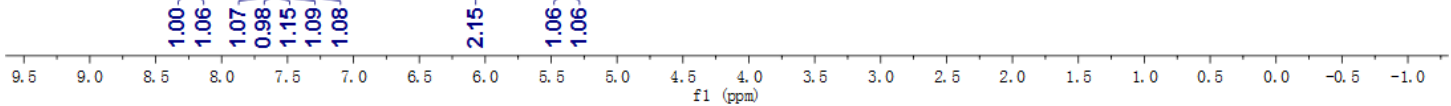



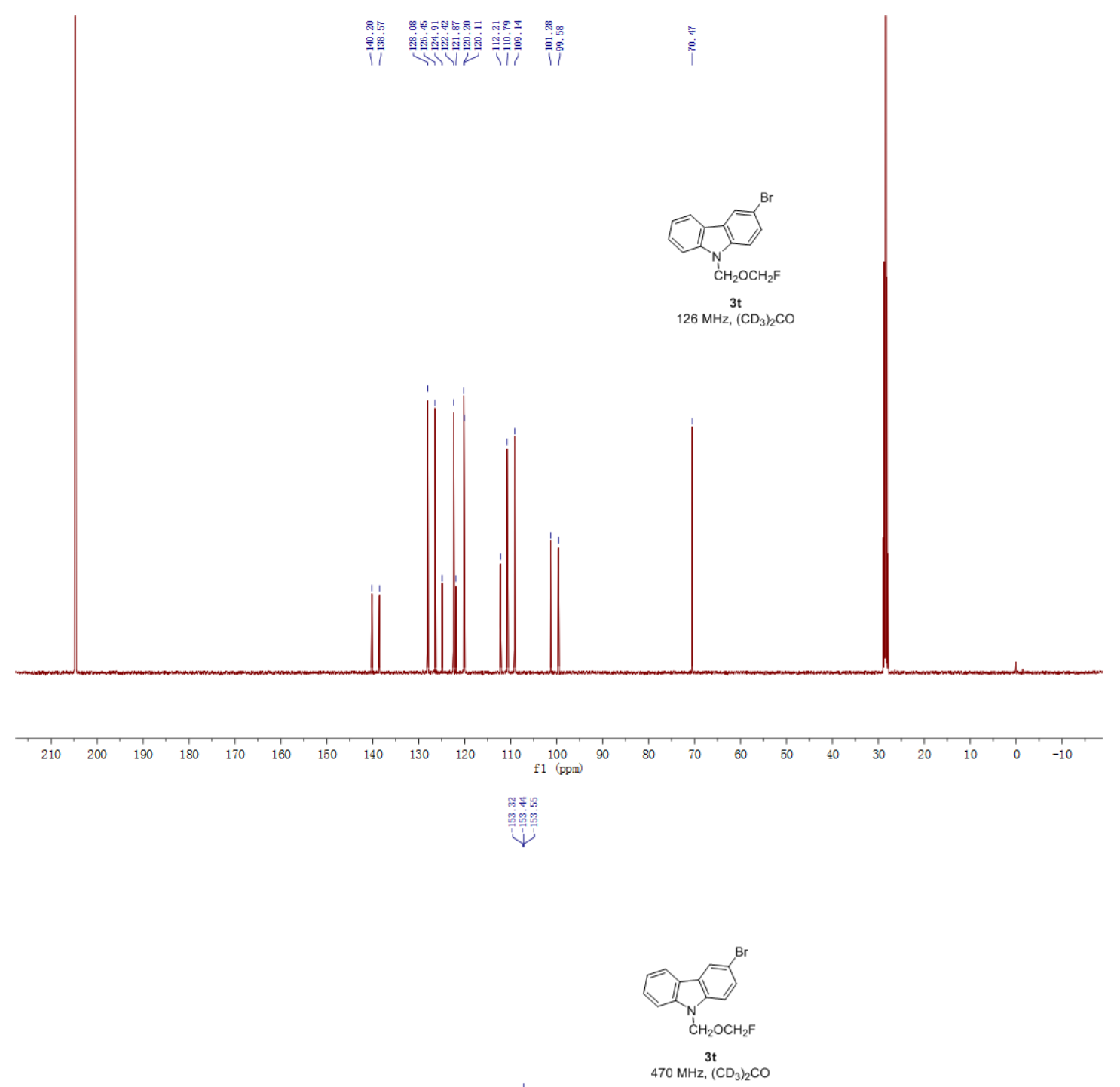

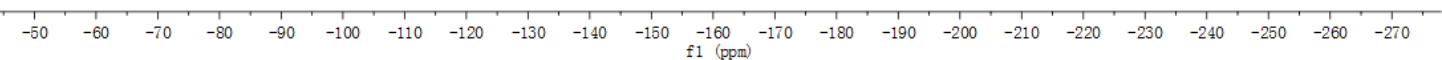



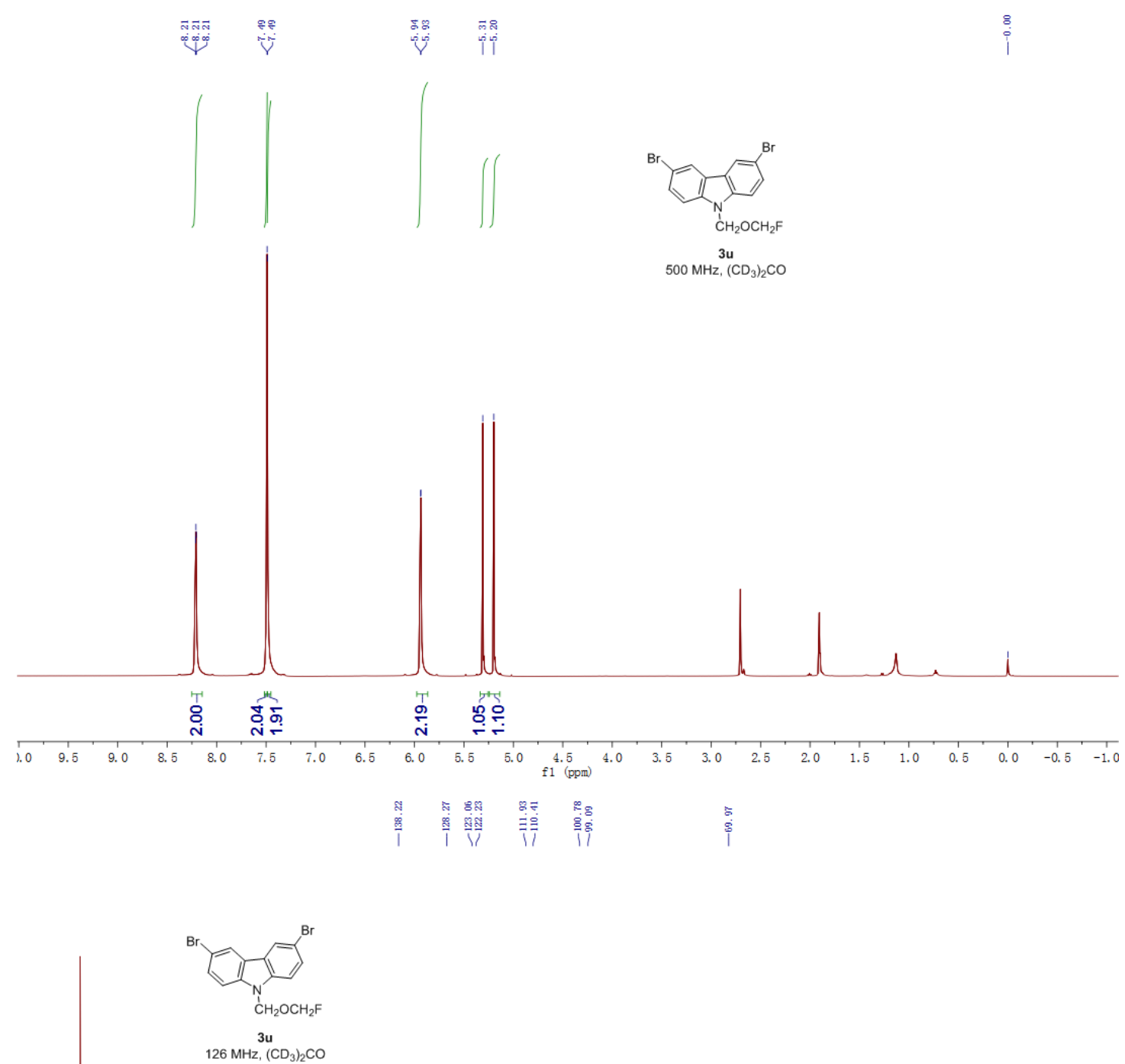

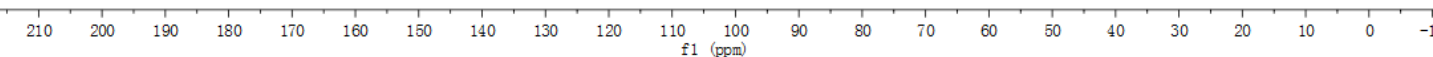



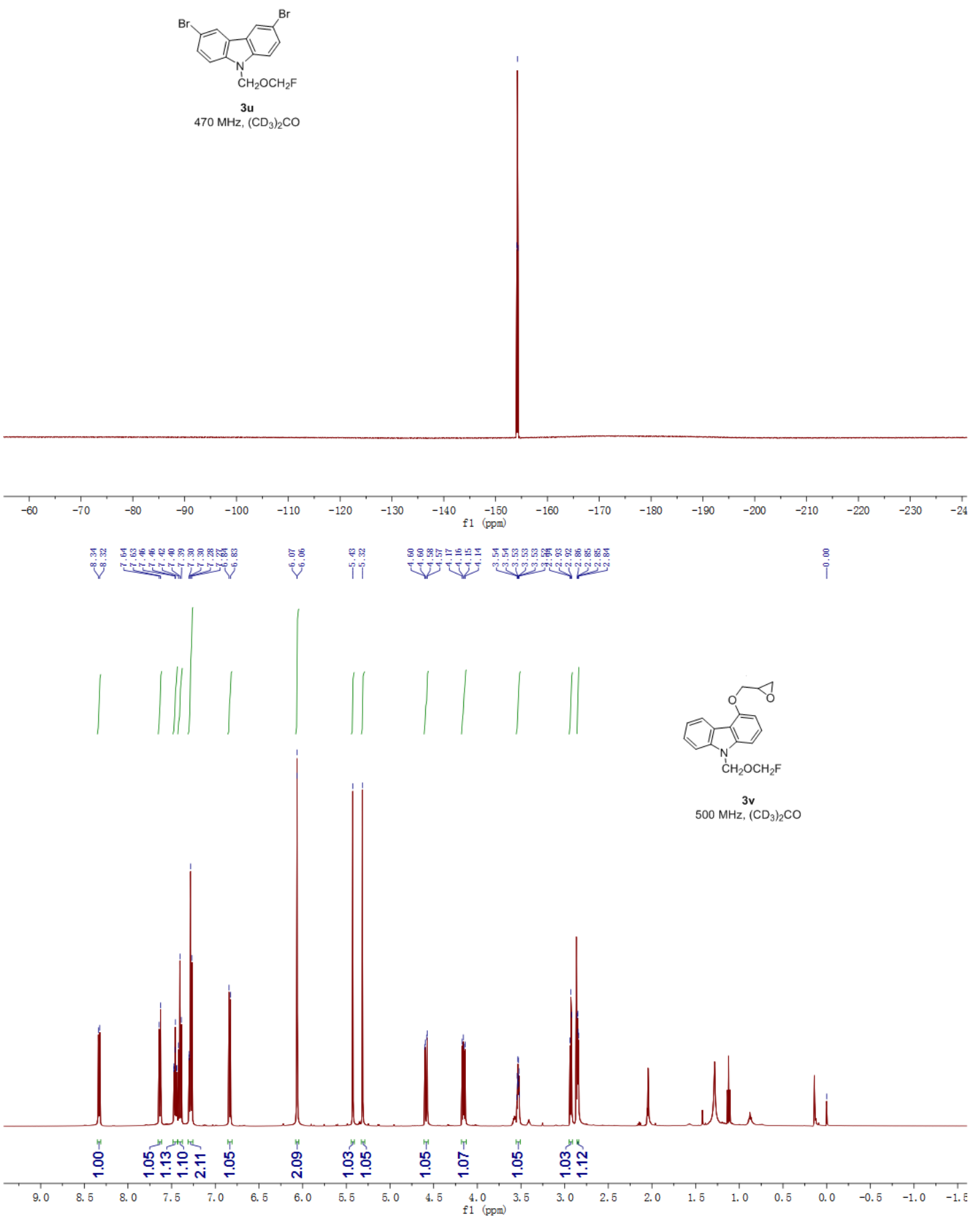


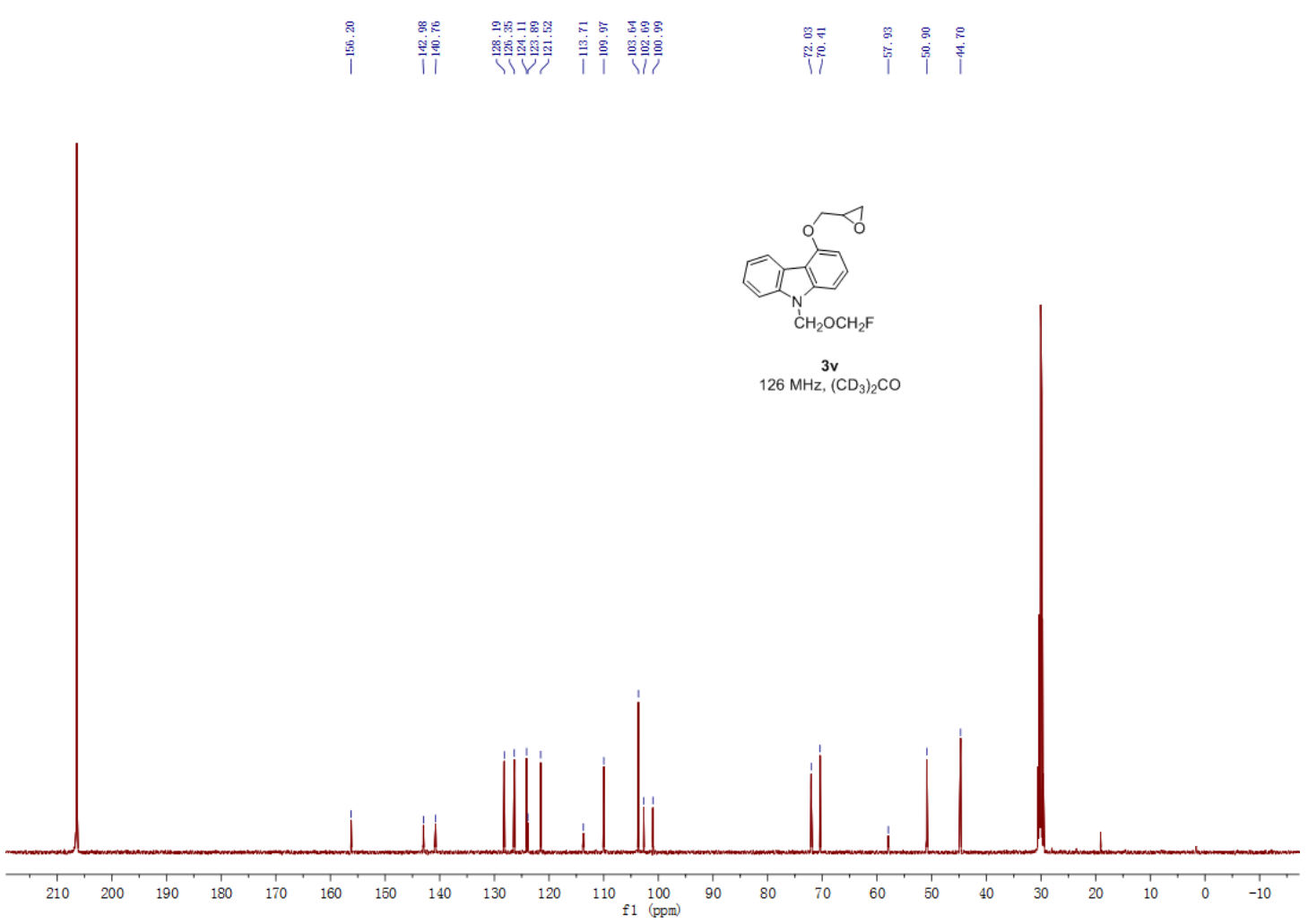

the

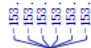

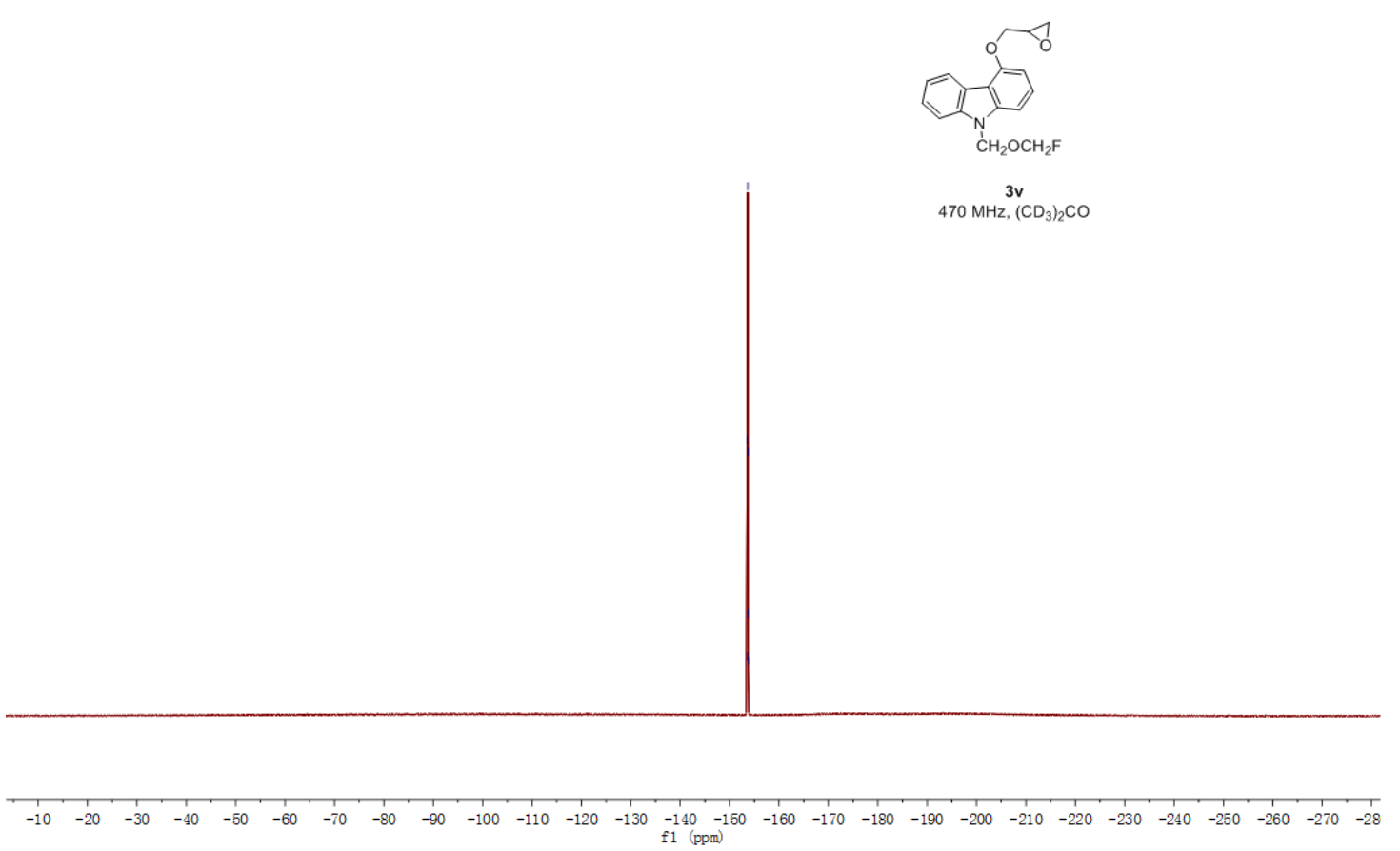




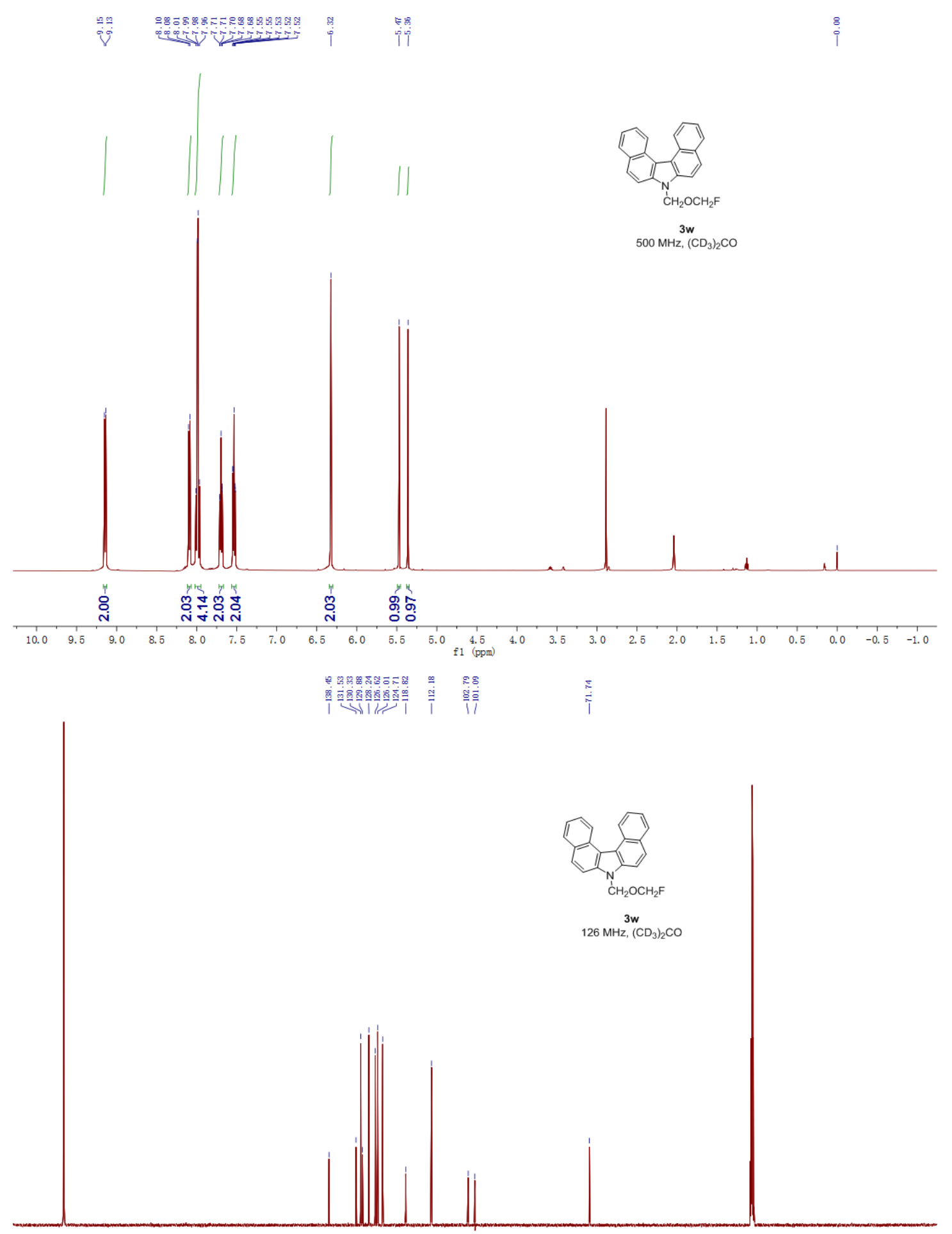

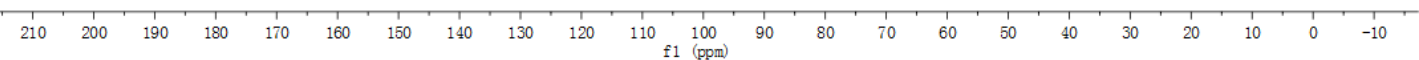




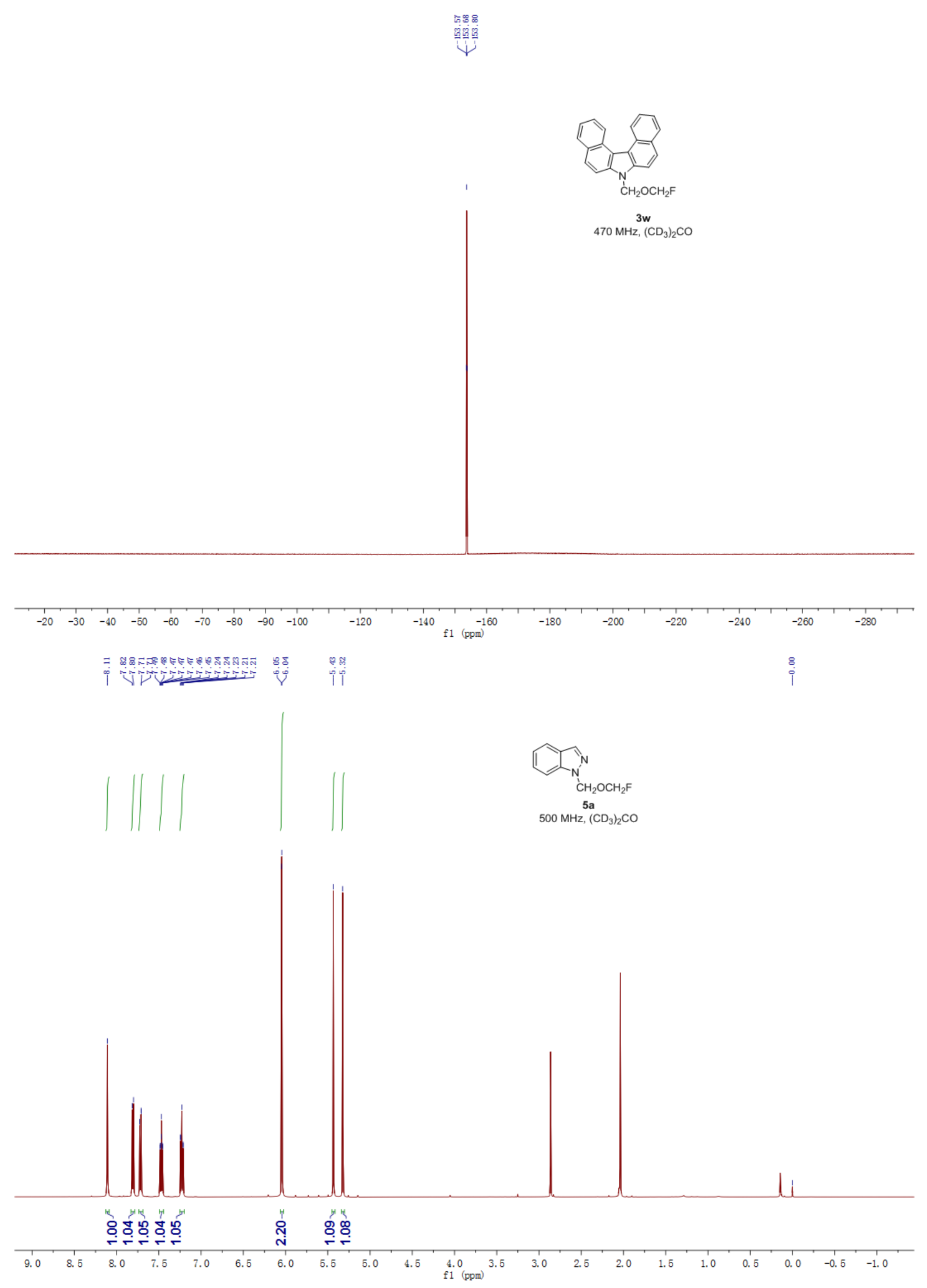




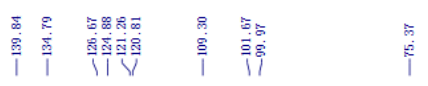
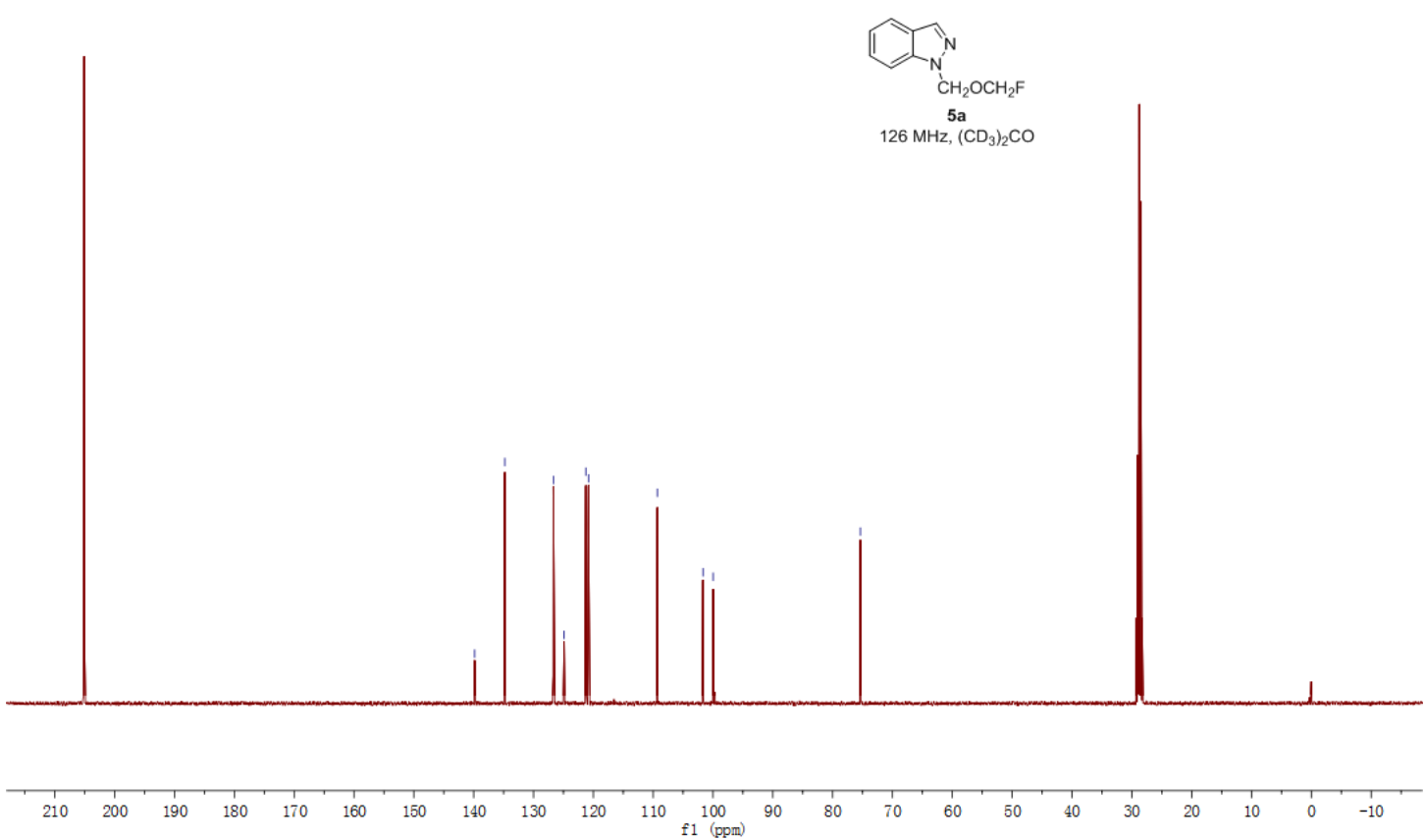

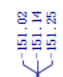

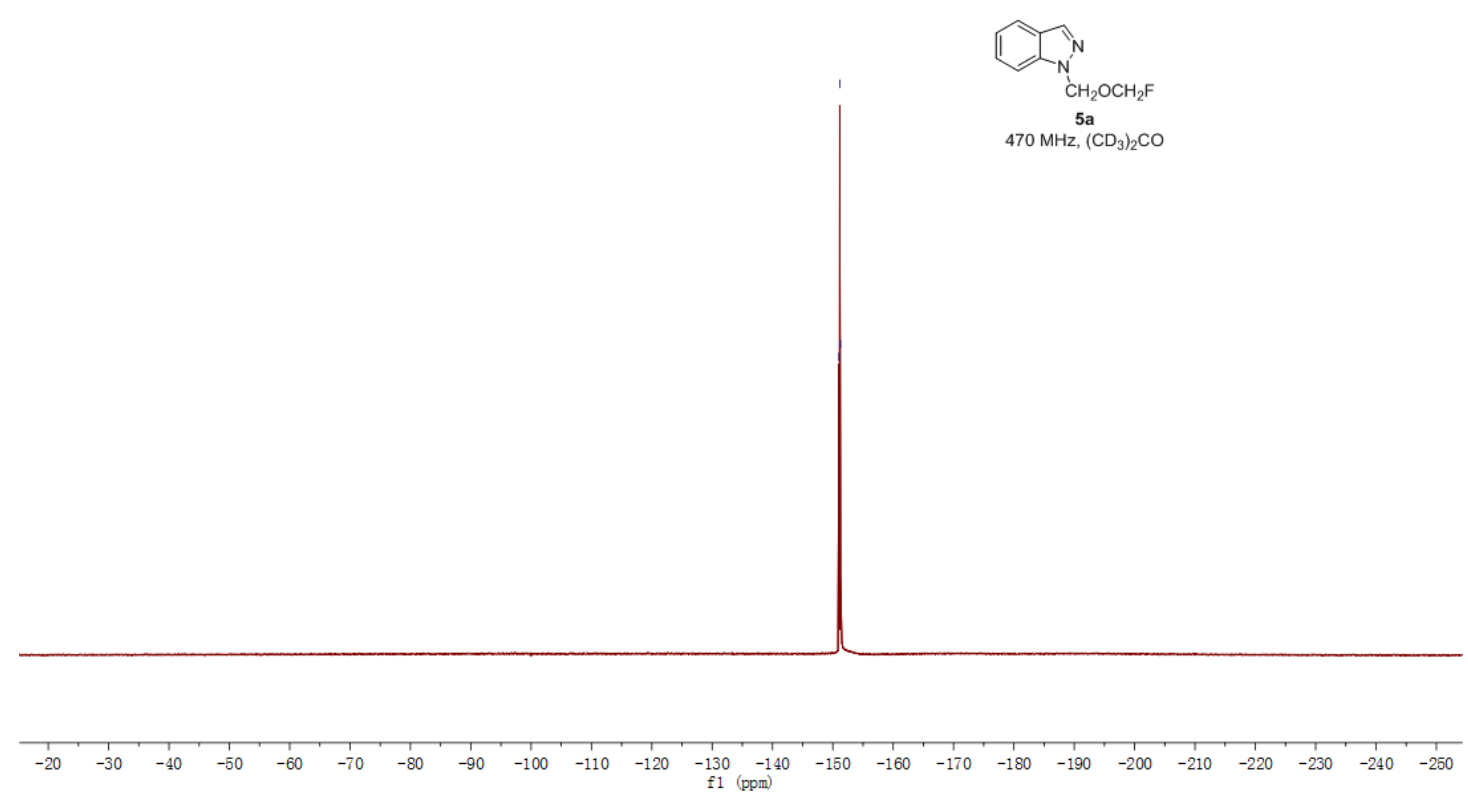



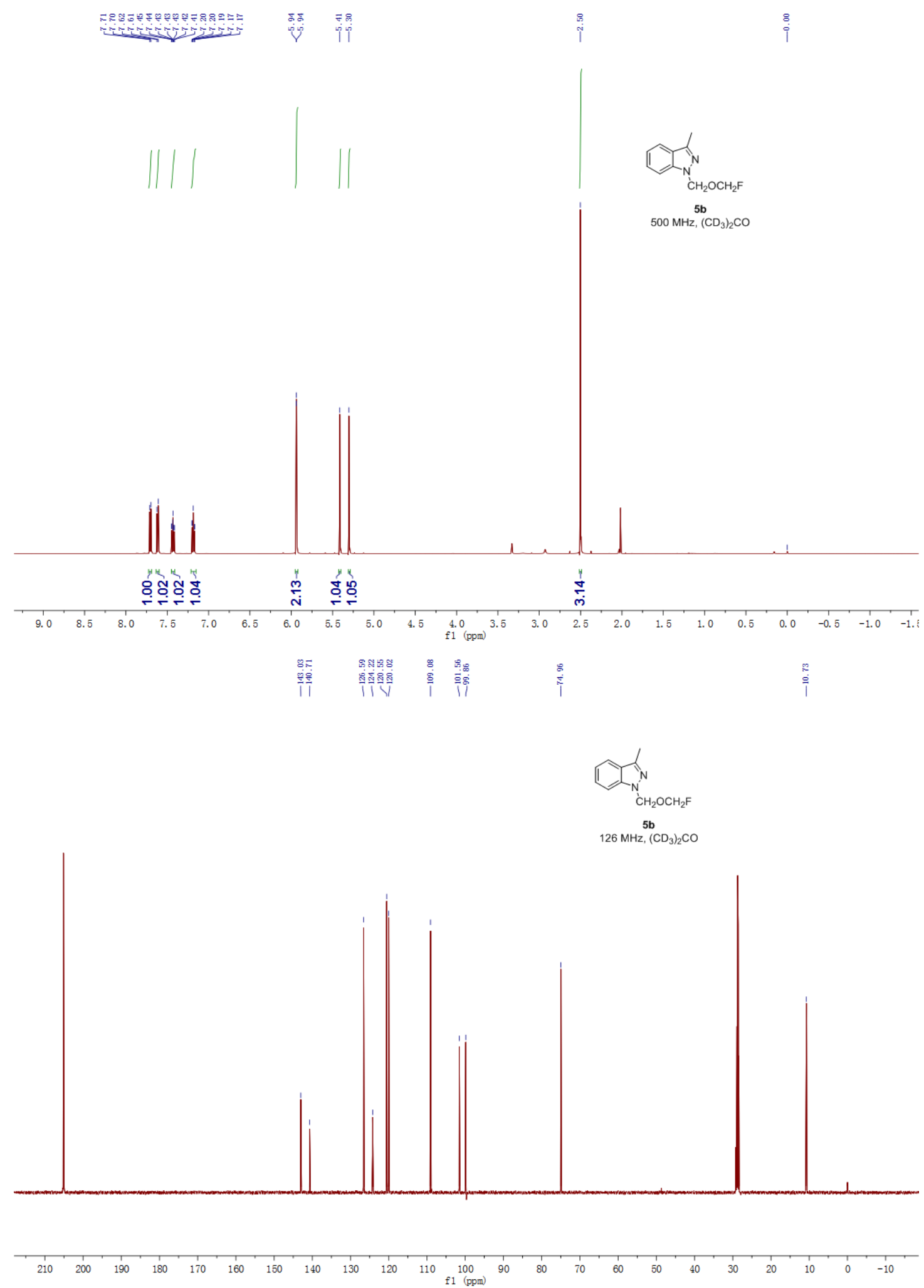


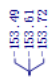
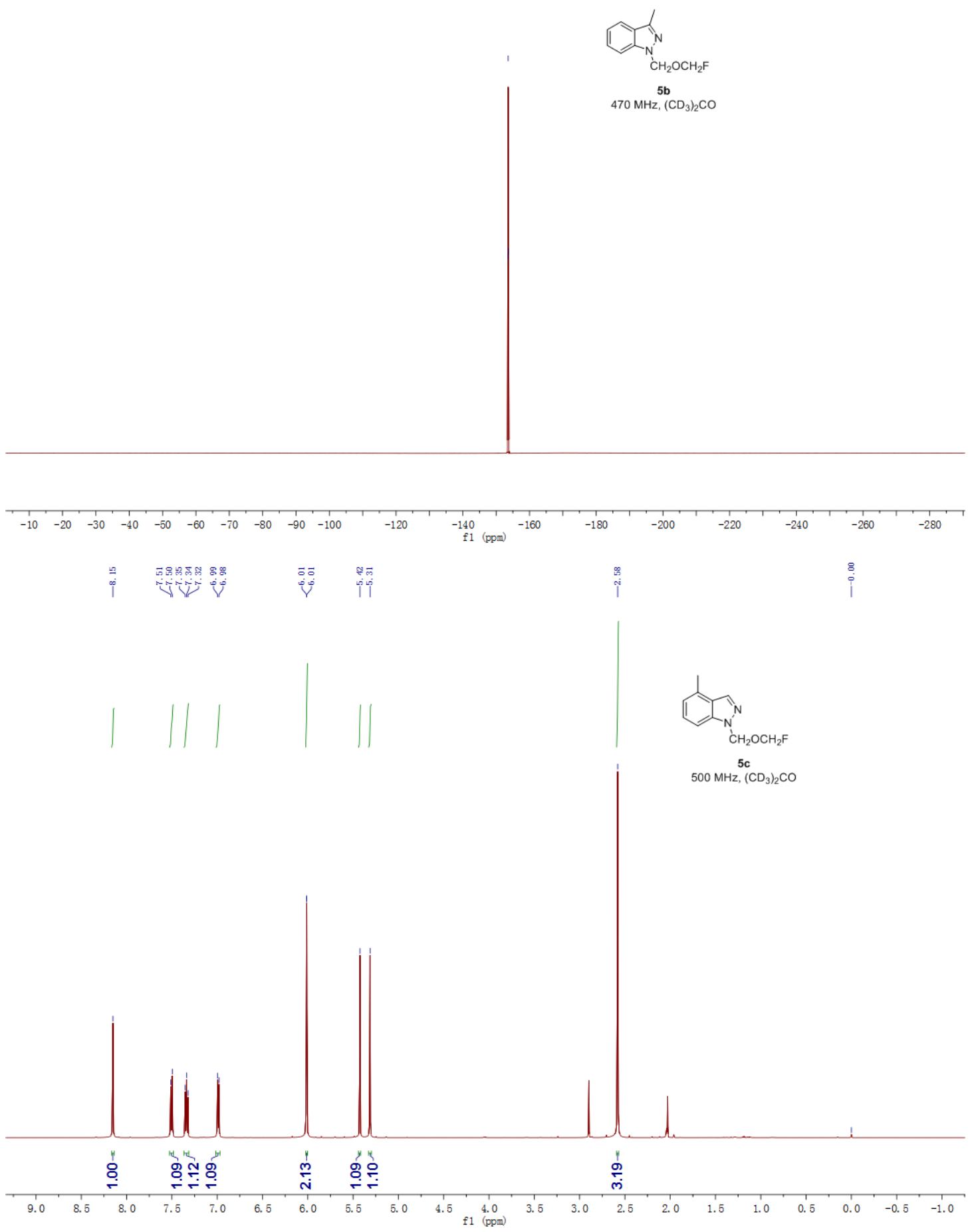

S41 

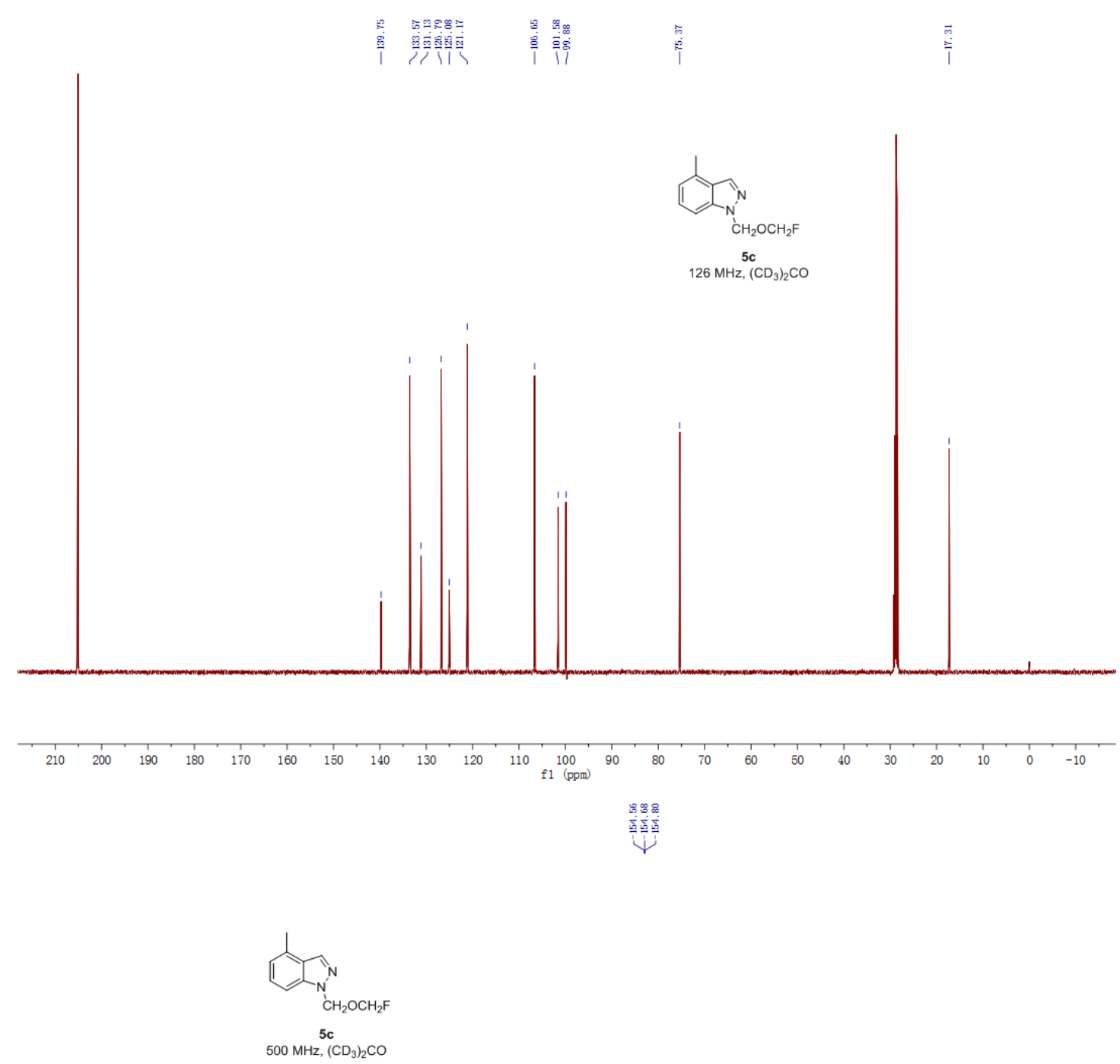

$\begin{array}{llllllllllllllllllllllllllllllllllllllll}T & 70 & -20 & -30 & -40 & -50 & -60 & -70 & -80 & -90 & -100 & -110 & -120 & -130 & -140 & -150 & -160 & -170 & -180 & -190 & -200 & -210 & -220 & -230 & -240 & -250 & -260 & -276\end{array}$ 


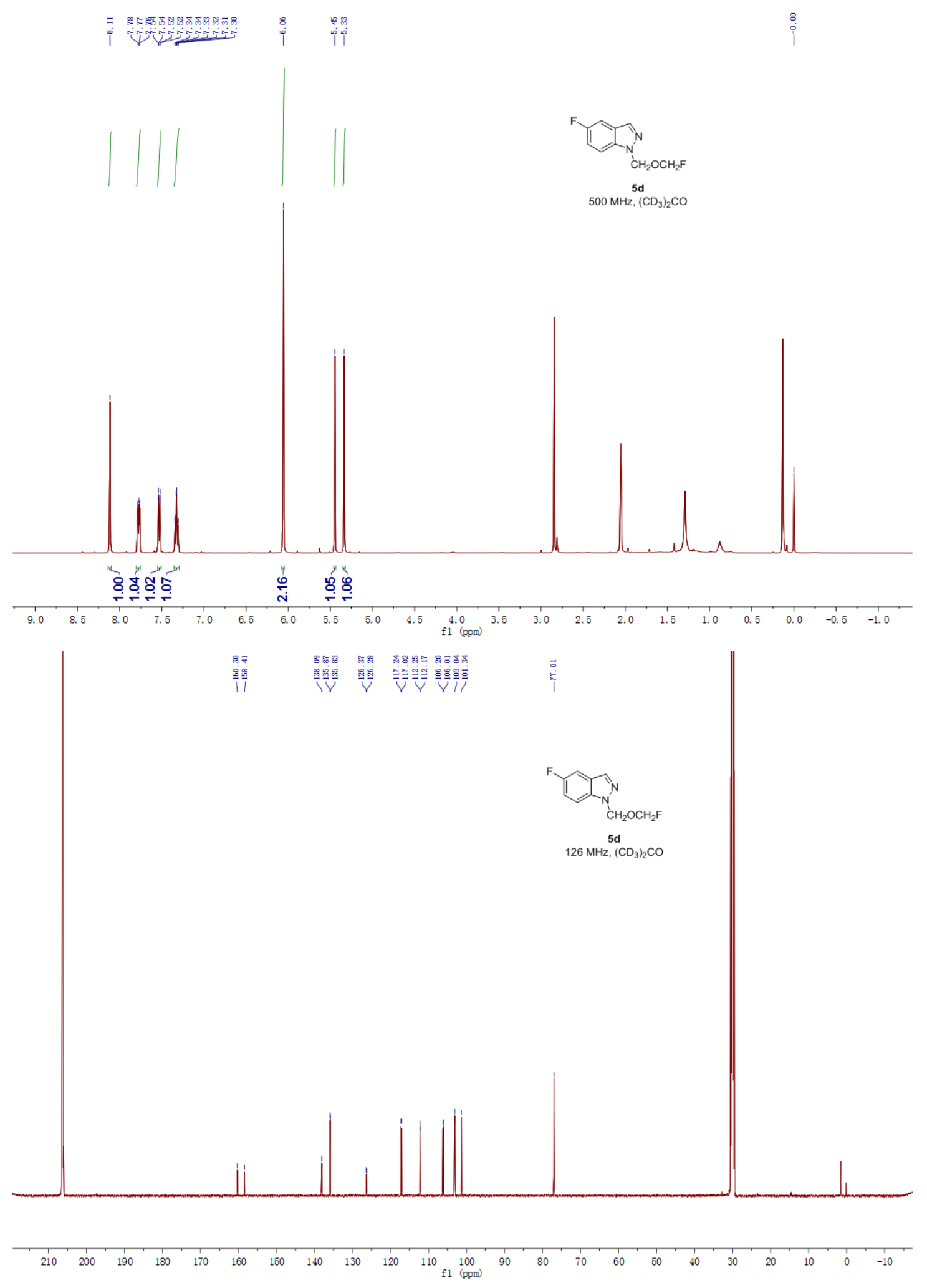




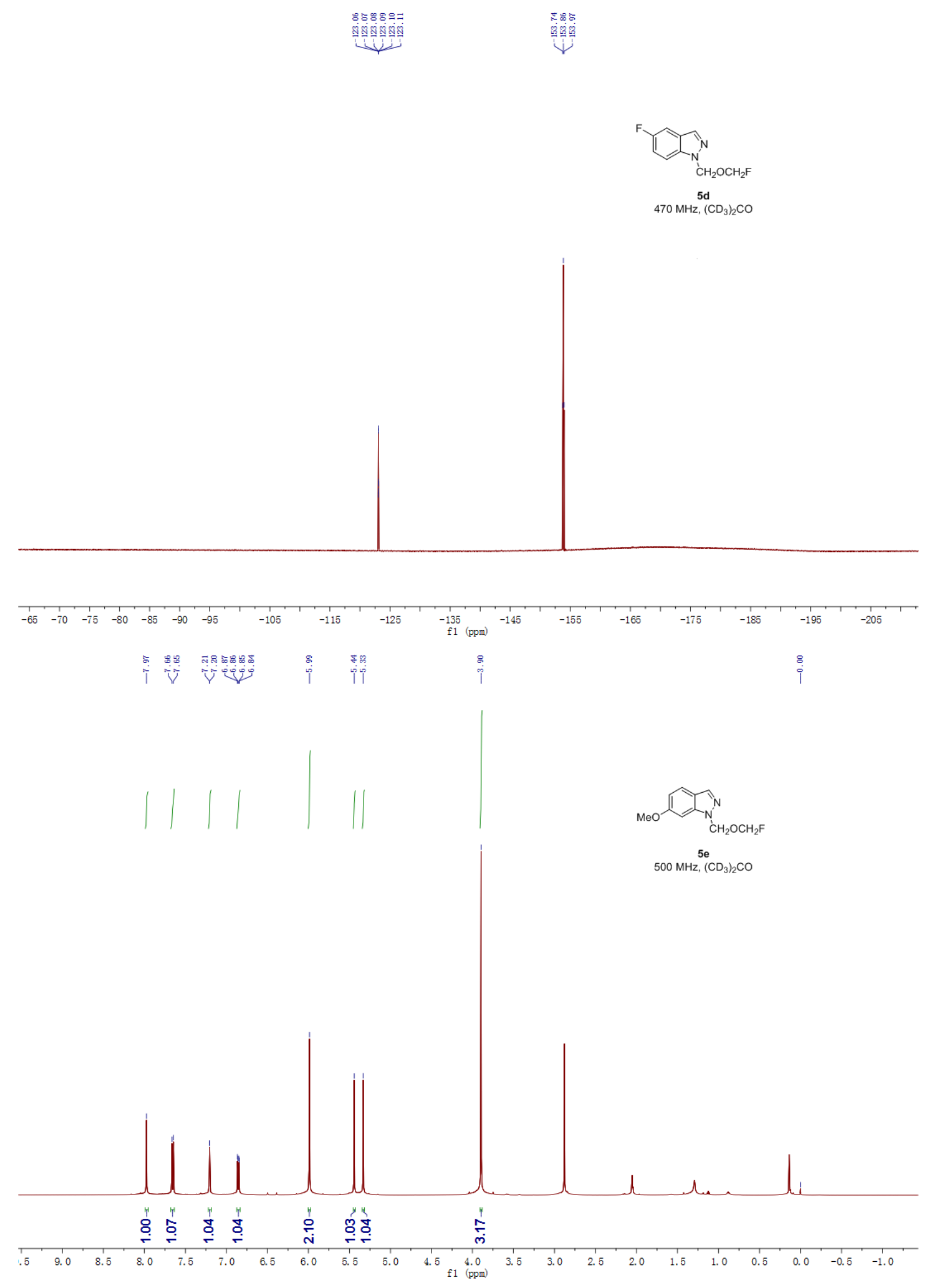



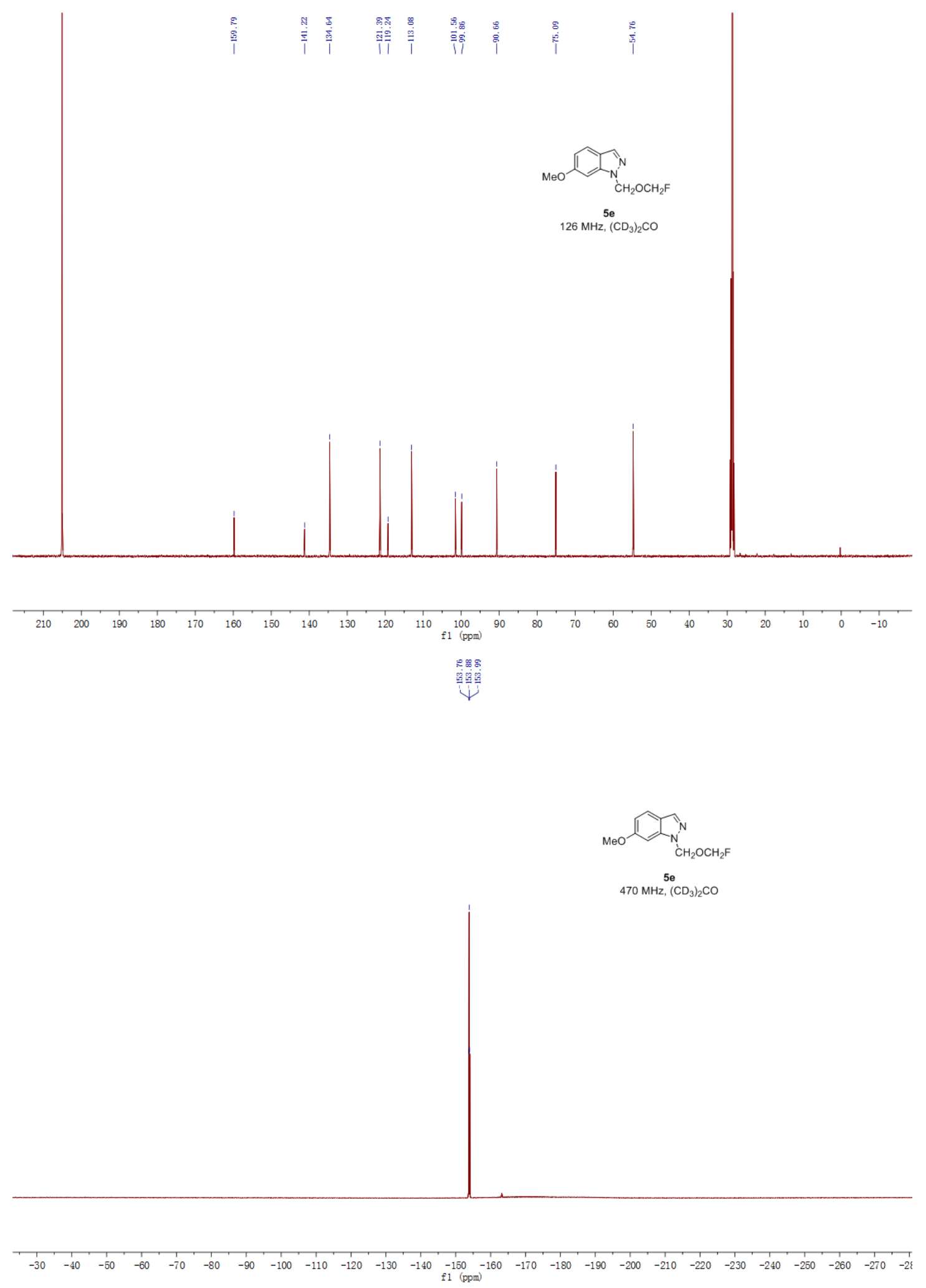


\section{X-Ray Crystallographic Data of 3q}

The white crystals of $\mathbf{3 q}$ were obtained by using the solvent vapor diffusion method in ether solution. Crystallographic data of complexes was collected at $296 \mathrm{~K}$ on a Bruker APEX-II CCD system equipped with graphite-monochromated Mo-K $\alpha$ radiation $(\lambda=$ $0.071073 \mathrm{~nm}$ ) using $\omega-\varphi$ scan technique. Diffraction data were integrated by the SAINT program, which was also used for intensity corrections for Lorentz and polarization effects. Semi-empirical absorption correction was applied using SADABS. The structures were solved by direct methods and all non-hydrogen atoms were refined anisotropically on $\mathrm{F}^{2}$ by full-matrix least-squares using the SHELXL-97 crystallographic software package.

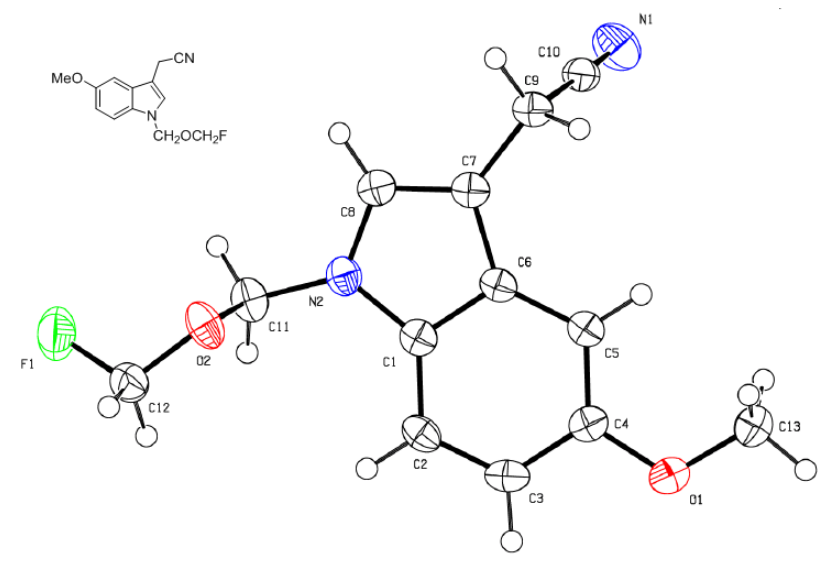

Thermal ellipsoids for $\mathbf{3 q}$ are shown at $50 \%$ probability level.

\begin{tabular}{|c|c|}
\hline Formula & $\mathrm{C} 13 \mathrm{H} 13 \mathrm{FN} 2 \mathrm{O} 2$ \\
\hline Formula weight & 248.25 \\
\hline Crystal system & Orthorhombic \\
\hline space group & $P 21$ \\
\hline$a(\AA)$ & $4.2319(3)$ \\
\hline$b(\AA)$ & $14.2453(9)$ \\
\hline$c(\AA)$ & $19.5737(12)$ \\
\hline$\alpha(\stackrel{\circ}{)})$ & 90.00 \\
\hline$\beta$ (ㅇ) & 90.00 \\
\hline$\gamma(\underline{0})$ & 90.00 \\
\hline Volume $\left(\AA^{3}\right)$ & $1179.99(13)$ \\
\hline$z$ & 4 \\
\hline$T(\mathrm{~K})$ & $173(2)$ \\
\hline$D_{\text {calcd }}\left(\mathrm{g} / \mathrm{m}^{3}\right)$ & 1.397 \\
\hline
\end{tabular}




\begin{tabular}{ll}
\hline$F(000)$ & 520 \\
Reflections collected & 2065 \\
Unique reflections & 1900 \\
Goof & 1.055 \\
$R_{1}[I>2 \sigma(I)]$ & 0.0342 \\
$W R_{2}[I>2 \sigma(I)]$ & $0.0886^{\mathrm{a}}$ \\
CCDC NO. & 1889210 \\
\hline $\left.12 P)^{2}+0.1488 P\right]$, where $\mathrm{P}=\left(F_{0}^{2}+2 F_{\mathrm{c}}^{2}\right) / 3 ;$
\end{tabular}

${ }^{\mathrm{a}} w=1 /\left[\sigma^{2}\left(F_{0}\right)^{2}+(0.0512 P)^{2}+0.1488 P\right]$, where $\mathrm{P}=\left(F_{0}^{2}+2 F_{\mathrm{c}}^{2}\right) / 3$ 